SPIRITUALITY, GENDER, AND SUPERVISORY

STYLE IN SUPERVISION

by

MARIANNE McINNES MILLER, B.A., M.M.F.T.

A DISSERTATION

IN

\title{
MARRIAGE AND FAMILY THERAPY
}

Submitted to the Graduate Faculty of Texas Tech University in

Partial Fulfillment of

the Requirements for

the Degree of

DOCTOR OF PHILOSOPHY

Approved

Chairperson of tho conminttee

Accepted

Dean of the Graduate School

December, 2003 


\section{ACKNOWLEDGEMENTS}

This dissertation has been a journey. Sometimes it felt like a deep, dark valley, and other times it seemed as if I were standing on a mountain peak. Throughout it all, my Lord God has guided, strengthened, protected, and gone before me.

Several other people have helped me significantly through the peaks and valleys. My precious husband, Mark, has not only loved and encouraged me every step of the way, he has also walked with me during my dark times. My parents, Peter and Carol McInnes, along with my brother, Doug, and my sister, Karen, have provided tremendous support, as well as helped me laugh when I felt stressed. I am thankful for how my dissertation chair, Dr. David Ivey, supported me as I followed my dream research topic. I also appreciate all of the feedback, reviews, and ideas from committee members: Dr. Alan Korinek, Dr. Madonne Miner, and Dr. Karen Wampler. I am grateful for the professors who opened the doors for my visits to numerous MFT programs around the United States: Dr. Todd Edwards (Univ. of San Diego), Dr. Jerry Gale (Univ. of Georgia), Dr. Shelly Haddock (Colorado State), Dr. Jackie Halstead (Abilene Christian), Dr. Carmen Knudson-Martin (Loma Linda), Dr. Janie Long (Purdue), Dr. Briana Nelson (Kansas State), Dr. Dan Ratliff (St. Mary's), and Dr. Scott Woolley (Alliant International). Lastly, I want to thank my amazing friends in Lubbock who helped review chapters, heard complaints, gave hugs, and provided lots of chocolate and support: Dr. Laura Bryan, Bobbi Miller, Nichole Morelock, Margaret Morgan, Dr. Ann Noble, Narumi Taniguchi, and Gayatri Titus. Thank you, everyone, for making it possible. 
ABSTRACT vii

LIST OF TABLES viii

CHAPTER

I. INTRODUCTION 1

$\begin{array}{ll}\text { Spirituality } & 1\end{array}$

Spirituality and Psychotherapy 2

Spirituality in Marriage and Family Therapy 4

$\begin{array}{lr}\text { Spirituality, MFT, and Supervision } & 6\end{array}$

Spirituality, MFT, Supervision, and Supervisory Style $\quad 7$

Gender, Spirituality, and

Supervisory Style in MFT Supervision $\quad 8$

$\begin{array}{ll}\text { Research Question } & 10\end{array}$

II. LITERATURE REVIEW 11

$\begin{array}{ll}\text { Spirituality } & 11\end{array}$

Definitions of Spirituality and Religion $\quad 11$

Spirituality in Therapy 14

$\begin{array}{ll}\text { Spirituality in MFT } & 15\end{array}$

Ethical Issues of Addressing Spirituality in MFT 18

Spirituality in Training and Supervision-Other Fields $\quad 19$

$\begin{array}{ll}\text { Clinical Psychology } & 19\end{array}$ 
Spirituality in MFT Training and Supervision 22

Addressing Spirituality of Trainees in Supervision $\quad 27$

$\begin{array}{lr}\text { Supervisory Styles } & 29\end{array}$

$\begin{array}{ll}\text { Feminist Theory } & 30\end{array}$

$\begin{array}{ll}\text { Postmodern Feminism } & 31\end{array}$

$\begin{array}{ll}\text { Feminism in MFT } & 32\end{array}$

Feminism in MFT Training $\quad 33$

Training Tools in Feminist Family Therapy 34

Feminist Family Therapy Supervision $\quad 35$

Theory of Power-Foucault 37

$\begin{array}{ll}\text { Foucault and Feminism } & 39\end{array}$

Power/Gender/Hierarchy Issues in Supervision $\quad 40$

Addressing Therapist/Supervisor Gender, Spirituality in Supervision, and Supervisory Styles at MFT Training Programs

$\begin{array}{ll}\text { Hypotheses } & 44\end{array}$

$\begin{array}{ll}\text { III. METHODS } & 46\end{array}$

$\begin{array}{ll}\text { Sample } & 47\end{array}$

Recruitment Process 49

$\begin{array}{lr}\text { Procedures } & 49\end{array}$

Variables of Interest 51 
Demographic Questionnaire $\quad 52$

Supervisory Styles Index (SSI) 53

Spiritual Issues in Supervision Scale (SISS) 55

$\begin{array}{lr}\text { Design } & 59\end{array}$

$\begin{array}{lll}\text { IV. RESULTS } & 65\end{array}$

Preliminary Analyses and Procedures $\quad 65$

Factor Analysis and Reliability Testing of the Spiritual Issues in Supervision Scale (SISS) with Primary Data

$\begin{array}{ll}\text { Total Score for the SISS } & 67\end{array}$

Total Score for the SSI Subscales $\quad 67$

Recoded Items for Therapist-Supervisor Pairing 68

Other Preliminary Analyses $\quad 68$

Primary Analysis: Testing the Research Hypotheses 69

$\begin{array}{ll}\text { Hypothesis 1a } & 69\end{array}$

$\begin{array}{ll}\text { Hypothesis } 1 \mathrm{~b} & 70\end{array}$

$\begin{array}{ll}\text { Hypothesis 2a } & 70\end{array}$

Hypothesis $2 b \quad 71$

$\begin{array}{ll}\text { Hypothesis 3a } & 72\end{array}$

$\begin{array}{ll}\text { Hypothesis } 3 b & 75\end{array}$

$\begin{array}{ll}\text { Hypothesis } 4 & 76\end{array}$

$\begin{array}{ll}\text { V. DISCUSSION } & 104\end{array}$

Overview of Main Research Question 104 
Development and Testing of the Spiritual Issues in Supervision Scale (SISS)

Spirituality and Supervisory Style

Gender and Supervisory Style

Spirituality and Gender

Clinical Implications/Recommendations

Limitations

Future Directions

APPENDIX
A. DEMOGRAPHIC QUESTIONNAIRE
135
B. SUPERVISORY STYLES INDEX (SSI)
140
C. SPIRITUAL ISSUES IN SUPERVISION SCALE (SISS)
143 


\begin{abstract}
This dissertation explores spirituality as a facet of marriage and family therapy supervision, which is a key component of training clinicians. Supervision is a complex process; therefore, it would seem that several factors shape how therapists-in-training perceive the conversations about spirituality in this context. The sex of therapist and sex of supervisor influences the experiences of supervisees, given that gender issues relate to power and hierarchy. Moreover, supervisory style has emerged as a key factor affecting therapist/supervisor interactions. This study, therefore, explores these issues using the following guiding question: Is gender associated with variations in perceptions of supervisory style and the frequency with which spiritual issues are addressed in supervision?
\end{abstract}




\section{LIST OF TABLES}

3.1 Demographics for All Respondents 60

$3.2 \quad$ Sex of Supervisors \#1 and \#2 64

4.1 Total Variance Explained-Initial Eigenvalues

for the Principal Component Analysis of the

Spiritual Issues in Supervision Scale (SISS)

4.2 Total Variance Explained-Extraction Sums and Rotation Sums of Squared Loadings for the Principal Component Analysis of the Spiritual Issues in Supervision Scale (SISS)

4.3 Rotated Factor Loadings for Items in the

Spiritual Issues in Supervision Scale (SISS)

4.4 Pearson Correlations for the Demographic Variables as

Correlated with the Supervisory Styles Index (SSI)

Subscales and the Spiritual Issues in Supervision

Scale (SISS) Total Score

4.5 Univariate Analysis of Variance for Scores on the

Affiliative/Authoritative Subscale of the

Supervisory Styles Index (SSI)

4.6 Univariate Analysis of Variance for Scores on the

Directive/Non-Directive Subscale of the

Supervisory Styles Index (SSI)

4.7 Univariate Analysis of Variance for Scores on the Self-Disclosing/Non-Self-Disclosing Subscale of the Supervisory Styles Index (SSI)

4.8 Means and Standard Deviations for Ratings of Supervisory Style by Sex of Therapist

4.9 Univariate Analysis of Variance for Scores on the Spiritual Issues in Supervision Scale (SISS) 
4.10 Means and Standard Deviations for Frequency of Spiritual Issues Addressed in Supervision by

Sex of Therapist

4.11 Univariate Analysis of Variance for Scores on the Affiliative/Authoritative Subscale of the

Supervisory Styles Index (SSI)

4.12 Univariate Analysis of Variance for Scores on the Directive/Non-Directive Subscale of the

Supervisory Styles Index (SSI)

4.13 Univariate Analysis of Variance for Scores on the Self-Disclosing/Non-Self-Disclosing Subscale of the Supervisory Styles Index (SSI)

4.14 Means and Standard Deviations for Ratings of Supervisory Style by Sex of Supervisor

4.15 Univariate Analysis of Variance for Scores on the Spiritual Issues in Supervision Scale

4.16 Means and Standard Deviations for Frequency of Spiritual Issues Addressed in Supervision by

Sex of Supervisor

4.17 Univariate Analysis of Variance for Scores on the Affiliative/Authoritative Subscale of the

Supervisory Styles Index (SSI)

4.18 Univariate Analysis of Variance for Scores on the Directive/Non-Directive Subscale of the

Supervisory Styles Index (SSI)

4.19 Univariate Analysis of Variance for Scores on the Self-Disclosing/Non-Self-Disclosing Subscale of the Supervisory Styles Index (SSI)

4.20 Means and Standard Deviations for Ratings of Supervisory Style by Sex of Supervisor and

Sex of Therapist

4.21 Univariate Analysis of Variance for Scores on the Spiritual Issues in Supervision Scale (SISS) 
4.22 Means and Standard Deviations for Frequency of Spiritual Issues Addressed in Supervision by

Sex of Supervisor and Sex of Therapist

4.23 Pearson's Correlations for the Supervisory Styles Index (SSI) Subscales and the Spiritual Issues in Supervision (SISS) Total Score 


\section{CHAPTER I}

\section{INTRODUCTION}

What [a] piece of work is man, how noble in reason, how infinite in faculties, in form and moving, how express and admirable in action, how like an angel in apprehension, how like a god!

-Hamlet, Act II, Scene II, (Shakespeare, 1974 version)

Buddha's First Noble Truth maintains that to live is to suffer, which suggests that none of us can escape pain in our lives (Borysenko, 1999). The thoughts of Thomas Keating, a well-known Cistercian monk and author, resonate with Buddha's truth, emphasizing that "[t]he human race, as a whole, is a sick species" (Keating, 1994, p. 72). To some degree, these ideas explain the work of therapists. In essence, we help people who suffer-who feel as if a sickness has penetrated their lives and relationships. As clinicians, we must recognize both the humanity and the spirituality of clients with whom we work. As we interact with each other as supervisors, therapists, and trainees, we need to respect the diverse experiences and perspectives of what people see as spiritual and divine.

\section{Spirituality}

Addressing spirituality in therapy has become a more prevalent, and perhaps more accepted, topic in the mental health field in the past decade. Several authors have emphasized the importance of integrating spirituality specifically into the Marriage and Family Therapy (MFT) context (Aponte, 2002; Carlson \& Erickson, 2001, 2002; Coffey, 
2002; Erickson, Hecker, Kirkpatrick, Killmer, \& James, 2002; Harris, 1998; Haug, 1998; Helmeke \& Bischof, 2002; Prest \& Keller, 1993; Stander, Piercy, MacKinnon, \& Helmeke, 1994; Trepper, 2002; Walsh, 1999; Wendel, 2003). This focus makes sense, given the belief systems of many clients living in the United States: A USA TODAY/Gallup poll in January, 2002, reported that at least 50 percent of Americans consider themselves religious, and an additional 33 percent see themselves as spiritual (Grossman, 2002).

This study explores spirituality as a facet of marriage and family therapy supervision. As an introduction to this research, the following paragraphs discuss the history and relevance of spirituality in relation to several areas: (1) Psychotherapy; (2) MFT; (3) MFT and supervision; (4) MFT, supervision, and supervisory style; and (5) Gender, MFT, supervision, and supervisory style.

\section{Spirituality and Psychotherapy}

Modern psychotherapy became known to the United States 90 years ago when Sigmund Freud visited Clark University. As members of a young psychiatric field uncertain of its own identity, North American clinicians and researchers readily embraced Freud's ideas, which included a strong move to reject and even pathologize spiritual beliefs (Brawer, Handal, Fabricatore, Roberts, \& Waja-Johnston, 2002; Kurtz, 1999). Brawer et al. (2002) contended that "[p]erhaps, in its attempt to distance itself from its philosophical roots, psychology eschewed the topics of religion and spirituality as nonempirical and inappropriate for study" (p. 203). If spirituality is not scientific enough 
for the mental health field, it seems that the secularization of mainstream Western society continues to deepen. Moreover, the separation of church and state in the U.S., coupled with the freedom to choose one's own religious beliefs, often translate into shunning spirituality in secular environments (Stander et al., 1994).

In Western countries, this split between spirituality and psychology continues today, as most counselors, psychologists, and therapists tend to be less religiously oriented than their clients (Brawer et al., 2002; Fukuyama \& Sevig, 1997; Schulte, Skinner, \& Claiborn, 2002). Interestingly enough, while Western countries were seeking rational and empirical explanations for human behavior, the Eastern world continued to embrace spiritual perspectives of both insight and therapeutic healing (Kurtz, 1999). Perhaps as U.S. society's worldview broadens, mental health scholars and clinicians will recognize the benefits inherent in accessing spirituality. Walsh (1999) asserted that " $[t]$ he very essence of the therapeutic relationship and meaningful change are ultimately spiritual in nature, fostering personal transformation, wholeness, and relational connection with others" (pp. 4-5).

William James was an American psychologist and philosopher who published the bulk of his work at the turn of the $19^{\text {th }}$ century. He viewed pure human experience as the essence and substance of the world, emphasizing that the spiritual universe emerges through what people see occurring in the physical world (Drabble, 1985). James (1902/1997) explains his paradigm in the following statement:

It is as if there were in the human consciousness a sense of reality, $a$ feeling of objective presence, a perception of what we may call "something there," more deep and more general than any of the special 
and particular "senses" by which the current psychology supposes existent realities to be originally revealed. (p. 62)

James discussed a transcendent quality within the human experience that the psychology field was not addressing at that time. Since James' work was published, other clinicians have emphasized how mental health and spirituality are integrated. Miller and Thorensen (1999) pointed out that before science-based mental health professions existed, the spiritual leader of the community often assumed the role of healer, such as the Mexican curandero and curandera, and the native shaman. This overlapping of roles still exists in many parts of the world. In the United States, scientific methodology has functioned as the foundation of medical treatment, which eventually created a rift between therapy and religion/spirituality (Kurtz, 1999; Miller \& Thorensen, 1999).

\section{Spirituality in Marriage and Family Therapy}

Marriage and family therapists (MFTs) tend to associate themselves with religious and spiritual traditions more than other mental health practitioners (Erickson et al., 2002; Prest \& Keller, 1993). It seems as if spirituality has become more important to MFTs in recent years, as evidenced by an increasing number of articles that have focused on this issue, either directly or indirectly (Blanton, 2002; Carlson, Erickson, \& SeewaldMarquardt, 2002; Erickson et al., 2002; Senter \& Caldwell, 2002). Carlson and Erickson (2002) asserted that MFTs are "addressing spirituality and religion more and more as we collectively have come to understand that for most peoples throughout the world, religion and/or spirituality occupy a very central aspect of culture on both macro and micro levels" (p. 1). Wendel (2003) agreed, emphasizing that in recent years "there has been an 
upsurge of discourse on spirituality within family therapy. This interest goes beyond seeing religion as no longer inherently pathological" (p. 165). In essence, there appears to be the beginning of a trend in MFT to recognize that integrating a client's spirituality and/or religion in therapy is a significant facet of culture (Carlson et al., 2002).

Despite this trend, several authors have lamented that most MFT graduate students are not receiving training on how to address spiritual issues (Coffey, 2002; Harris, 1998; Haug, 1998; Helmeke \& Bischof, 2002; Patterson, Hayworth, Turner, \& Raskin, 2000; Prest, Russel, \& D'Souza, 1999). In the literature, there have been opinions as to why this area is overlooked. Harris (1998) asserted that "spiritual biases" may exist in family therapy models, which serve as the theoretical foundation of MFT. Wendel (2003) discussed that the problem lies in the difficulty in defining spirituality. He explained that current clinical literature seems to include ever-expanding meanings of spirituality, which often creates ambiguity when clinicians and researchers attempt to integrate the term into their work. Helmeke and Bischof (2002) cited many factors explaining the hesitancy to incorporate spirituality in therapy and training:

Some of the reluctance stems from values held by the therapists, such as respect for the client. Many therapists, as part of their training, have been taught to be cautious about imposing their values and beliefs on clients, out of respect for them. For others, the reluctance involves a lack of training, and therefore confidence, in knowing how religious and spiritual issues can be integrated appropriately into therapy. (p. 196)

Regardless of the reason, it appears that many MFTs struggle with figuring out how spirituality intersects with clinical work, even though they may be more religiously oriented than other mental health professionals. 


\section{Spirituality, MFT, and Supervision}

Harris (1998) discussed how MFT training programs tend to overlook spiritual issues, emphasizing (along with Frame, 2001; Prest \& Keller, 1993) that unless trainees attend programs that espouse spiritual beliefs, spirituality is rarely addressed. Supervision is an essential part of MFT training, both during graduate school and working toward licensure. Watson (1993) described it as "one of the spokes in the evolving wheel of marriage and family therapy" (p. 21). She depicted it as a socialization process—one in which clinicians become familiar with a new and expanding field. Such a socialization process creates a setting in which both trainees and supervisors could address spiritual issues (Carlson \& Erickson, 2001). At the same time, given the personal (and often highly emotional) nature of spirituality, as well as the strained relationship between the mental health field and spirituality, supervisors may hesitate to talk about this area, and supervisees tend to follow their lead (Miller, 1999; Stander et al., 1994; Wendel, 2003).

Although several pieces of literature previously mentioned in this chapter discussed integrating spirituality into the therapeutic process, little research has emerged that examines spiritual issues as a dimension of MFT training and supervision. Indeed, Coffey (2002) pointed out that "spirituality has not gained a foothold for many researchers and, hence, has struggled to define itself in peer-reviewed literature" (p. 29). Prest, Russel, and D'Souza (1999) examined the perspectives of MFT graduate students on spirituality, practice, and training. Their results suggested that although students valued spirituality, they did not feel comfortable discussing it in professional contexts. 
Apparently few participants had received training on how to integrate spirituality into therapy; therefore, most of them did not believe that they had strong skills in this area. It would seem important, then, to explore more specifically how much spirituality is being addressed in a crucial aspect of MFT training-namely, supervision. Although there is no current consensus in clinical literature, due in part to the lack of a common definition of spirituality, some recent authors have argued that spirituality is a construct to consider in this area (Bava, Burchard, Ichihashi, Irani, \& Zunker, 2002; Coffey, 2002; Carlson et al., 2002; Frame, 2001; Haug, 1998; Patterson, Hayworth, Turner, \& Raskin, 2000).

\section{Spirituality, MFT, Supervision, and Supervisory Style}

In addition to the lack of training and knowledge of how to integrate spirituality into MFT training, supervisory style may contribute to an individual's reluctance to explore this area in supervision. It seems that supervisory style is a significant component of the supervisor/therapist relationship. Given the power differential inherent in supervision, therapists likely follow the supervisor's lead on whether or not to address spirituality in supervision. Moreover, the personal (and highly emotional) nature of spirituality may contribute to supervisors' hesitancy to talk about it (Miller, 1999;

Stander et al., 1994). Unfortunately, silence sends the message that the topic is irrelevant, if not taboo (Miller, 1999).

In order to train culturally sensitive therapists, supervisors need to create a safe environment in which trainees feel comfortable to discuss their unique cultural lenses, prejudices, and blind spots (Watson, 1993). Carlson et al. (2002) discussed the 
importance of teaching therapists to use their own spiritual lives as a resource in their clinical work. It seems that a spirit of openness and respect in the way supervisors and supervisees relate to each other would generate an atmosphere conducive to discussing such a personal and emotionally laden issue as spirituality (Bava et al., 2002). This idea emerged in a study of supervisees' best and worst supervision experiences in which researchers generated four categories that highlight the critical factors of participants' best experiences (Anderson, Schlossbert, \& Rigazio-DiGilio, 2000). In general, these categories advocated demonstrating support and respect in supervision, as well as allowing for open discussion of difficult, anxiety-laden issues to provide a catalyst for personal growth. Some specific characteristics of poor supervisory experiences in the area of openness in supervision were supervisors who assume authoritarian and demeaning stances, fail to accept divergent perspectives, and devalue the therapists on the basis of gender (Anderson et al., 2000). Supervisory style, therefore, is a component to consider if spirituality indeed can be addressed more easily through open, respectful conversation throughout the supervision process.

\section{Gender, Spirituality, and Supervisory Style in MFT Supervision}

As we become sensitive to the multiple perspectives of clients, we acknowledge the diversity inherent in therapists and supervisors as well. Gender serves as a significant part of this diversity. It permeates all interactions, functioning as a lens through which people interpret and classify the world (Chaney \& Piercy, 1988; Haddock, Zimmerman, \& MacPhee, 2000; Miller \& Wieling, 2002; Osmond \& Thorne, 1993). Supervision is an 
essential part of the marriage and family therapy (MFT) field, providing the training and guidance needed to grow as clinicians. Given the significance of gender, it seems that being male or female, as well as having a male or female supervisor, would shape one's experience in supervision. Gender not only influences how both parties interact, but also how they interpret their experiences. Moreover, the gender of the therapist and the gender of the supervisor would influence how they discuss certain topics.

Although COAMFTE requires accredited programs to educate students in genderinformed principles, it appears that therapists still do not translate this information into practice (Chaney \& Piercy, 1988; Haddock et al., 2000). Haddock et al. (2000) asserted that " $[\mathrm{m}]$ any therapists may fail to engage in gender-informed practice not because they reject feminist principles but because they do not know how to enact them" (p. 153). Likewise, Chaney and Piercy (1988) emphasized the need to teach feminist and gendersensitive skills that apply specifically to MFT, drawing from the expertise of feminist family therapists. Even if students choose not to embrace feminist ideals, it is still necessary to recognize gender issues in therapy, as "[f]ailing to do so will result in therapists providing less effective treatment, and most likely, even unwittingly causing harm to clients" (Zimmerman \& Haddock, 2001). Furthermore, the diversity in today's clientele requires clinicians to become skilled at working with different types of people; thus, therapists without training in this area will be disadvantaged (Zimmerman \& Haddock, 2001). Even though feminist-informed family therapy has been a part of the MFT field for more than 20 years, scholars have given little attention to gender issues in family therapy training (McDaniel, Lorenz, Waxman, \& Kotze, 1995; Prouty, Thomas, 
Johnson, \& Long, 2001). It seems important, therefore, to explore not only how gender influences the therapeutic process, but also how it affects training, especially within the supervisory context.

A feminist perspective highlights the hierarchy inherent in the supervisory relationship, aiming to reduce the power differential between therapist and supervisor while attending to issues of gender, power, and oppression (Prouty, 2001). Such issues are important in supervision. At the same time, feminists in general do not focus on spirituality in this arena, even though society often associates oppression, power struggles, and gender roles with spiritual matters. It would appear important, then, to examine how the gender of the supervisor and the gender of the therapist influence discussions about spirituality.

\section{$\underline{\text { Research Question }}$}

The reason therapy is needed is because people suffer and have, to some degree, a sickness in their lives and relationships. Given this need, and given that we must acknowledge the complexities of human beings, perhaps we ought to consider spirituality as we train therapists. The guiding focus of this study, therefore, is addressing spirituality in MFT training. The specific research query pinpoints different facets of spirituality in training, and it emerges as the following question: Is gender associated with variations in perceptions of supervisory style and the frequency with which spiritual issues are addressed in supervision? 


\section{CHAPTER II}

\section{LITERATURE REVIEW}

Those folks did not understand what had happened to him. They had been playing the bingo game day in and night for years, trying to win rent money or hamburger change. But not one of those wise guys had discovered this wonderful thing. He watched the wheel whirling past the numbers and experienced a burst of exaltation: This is God! This is the really truly God! He said it aloud, "This is God!"

-Ralph Ellison, King of the Bingo Game (p. 342)

\section{Spirituality}

People experience and define spirituality in myriad ways. For one person, it may appear in a solemn church service filled with ritual. For another individual, it emerges through a gust of wind on the treeless mountaintop. It could become present through the gentle sigh of a baby or through a determined athlete's push to the finish. When working as supervisors and therapists, we need to approach people with an openness to all perceptions of spirituality, recognizing that how human beings experience the divine (or how they may not experience it) reflects their unique personalities, cultures, contexts, and histories. The following sections first present definitions of spirituality and religion found in the literature; they then address how authors have discussed spirituality in therapy, supervision, and training.

\section{Definitions of Spirituality and Religion}

Authors view spirituality and religion differently as constructs. In general, the literature falls into two groups when defining spirituality and religion. As authors in the 
first, larger category understood religion and spirituality as separate entities, the second group saw them as synonymous (Brawer et al., 2002). In the first category, the literature defined religion as a formal, organized belief system or social institution that promotes moral values and involvement in a community of believers (Miller, 1999; Walsh, 1999). Authors characterized religion by its prescribed rituals, practices, and beliefs (Miller \& Thoresen, 1999). Walsh (1999) contended that each ritual often holds significant meaning that connects individuals and families with the larger faith community. The term religiosity is used sometimes to define a person's specific beliefs and practices relative to religion (Miller \& Thoresen, 1999). Fukuyama and Sevig (1997) viewed religion as a means through which people express and experience their spirituality-something that can serve to nurture a spiritual life.

Given that religion is a highly personal and controversial construct, authors in this group disagreed about its degree of importance. While Miller (1999) asserted that religion is one-dimensional and often unimportant in understanding someone's spirituality, Walsh (1999) emphasized that a person's religion can correlate with her or his identity—both individually and within a family system. Judaism, for example, "is centered on the family observance of rituals, from weekly Shabbat (Sabbath) candle lighting to the major holidays in the Jewish calendar year and rites of passage across the life cycle" (Walsh, 1999, pp. 5-6). These rituals not only provide people with a sense of bonding with their larger community, but also with Jewish history, which emphasizes maintaining a covenant with God and surviving over adversity (Walsh, 1999). It seems 
that such reminders and affirmations help families and individuals reach beyond themselves to find identity and strength.

For those that defined spirituality and religion separately, spirituality emerged as a less precarious construct. Kurtz (1999) examined the history of the term spirituality through the eyes of theological commentators, concluding that spirituality appears less as a method or type of practice, and more as an attitude. He stated that "[t]he goal of spirituality is the alleviation of mental, emotional, and spiritual distress thought to be at least in part caused by the lack of an appropriate relationship with the ultimate reality" (Kurtz, 1999, p. 20). Miller (1999), as well as Miller and Thoresen (1999), viewed spirituality as a part of every person-something that is multidimensional and complex. Indeed, if an individual searches for meaning in life and/or a relationship with a higher or transcendent power, he or she experiences spirituality (Fukuyama \& Sevig, 1997). Walsh (1999) understood spirituality as an overarching construct that one can experience both within and outside of religious organizations. Overall, it appears that spirituality is a more personal experience of connecting with a transcendent power, while religion involves a community of believers and an organized form of worship.

Several authors did not make a clear distinction between spirituality and religion. Carlson and Erickson (2000) used these terms interchangeably, emphasizing that presenting different definitions of the two terms suggests a dichotomy that may not be useful to some people. Instead, they preferred to let the readers read religious/spiritual in whatever way they find helpful. Likewise, in Brawer et al.'s (2002) study, they combined the two words as religion/spirituality to provide participants with the broadest possible 
interpretation. Schulte et al. (2002) maintained that spirituality and religion have overlapping meanings; however, the authors did not consider these terms interchangeable. They contended that one can use religion to define some value systems and traditions more than others; spirituality tends to be more inclusive, applying to broader, cross-cultural beliefs and experiences. In their research, Schulte et al. (2002) used the words together, instructing participants to view spiritual and religious broadly as they filled out the surveys.

For the purposes of this study, spirituality will be defined in the broadest sense as an overarching construct that includes a personal journey of transcendent beliefs and a sense of connection with other people, experienced either within or outside formal religious structures.

\section{Spirituality in Therapy}

Addressing spirituality in therapy has become a more prevalent, and perhaps more accepted, topic in the mental health field in the past decade. The new interest in this area seems to come from the focus on diversity as it relates to gender, culture, race, ethnicity, and spirituality/religion (Griffith \& Rotter, 1999). Authors discussed how spirituality is an important issue to address in therapy, given the degree to which it relates to individual and family functioning. Gorsuch and Miller (1999) emphasized the need to assess spirituality in individual therapy, citing research suggesting that spiritual/religious factors may predict health outcomes. Miller and Thoresen (1999) explained that spiritual leaders' roles as healers in many cultures indicate that many people view their mental, physical, 
and spiritual well-being as interrelated. They stated that for many people living in the U.S., "the first professional sought out in time of crisis is still a member of the clergy, often their own pastor, priest, or rabbi" (p. 10). Indeed, several cultural groups within the United States, such as African-Americans and Latinos/Hispanics, tend to seek clergy members for counseling assistance significantly more than they access therapists (BoydFranklin \& Lockwood, 1999, Falicov, 1999). In the area of family, Griffith and Rotter (1999) affirmed that most religious systems concentrate on the family unit. These authors suggested that several world religions (Islam, Judaism, Christianity, Hinduism, Confucianism, etc.) specifically link family life and religion. Like Gorsuch and Miller (1999), Griffith and Rotter (1999) maintained that spirituality can positively influence the mental health of families and individuals. At the same time, they cautioned that not all forms and interpretations of spirituality and religion can benefit people, pointing out that prejudiced, exclusionary, and self-serving attitudes often are cultivated in religious organizations.

\section{Spirituality in MFT}

In the field of marriage and family therapy, several authors focused on integrating spirituality within the therapeutic process. Walsh (1999) has edited an entire book addressing spirituality in family therapy, emphasizing that "[t]he very essence of the therapeutic relationship and meaningful change are ultimately spiritual in nature, fostering personal transformation, wholeness, and relational connection with others" (pp. 3-4). Prest and Keller (1993) wrote one of the cornerstone articles of spirituality in MFT, 
challenging therapists to explore the spiritual beliefs of their clients-beliefs that either have edified and sustained family systems or created and maintained their problems. Stander et al. (1994) continued the discussion, suggesting that spirituality and family therapy often overlap in their roles. For example, therapy can help people gain a sense of perspective and create meaning in their lives-so can spirituality. Often different circumstances and experiences in people's lives lead to a stronger focus on spirituality. Harris (1998) pointed out that many spiritual experiences center on significant life transition points, such as birth and death. It is these times in which clients ask themselves the meaning of it all. The wake of the September 11,2001, terrorist attack in the United States inevitably led to MFTs watching clients wrestle with spiritual issues as they attempted to understand such trauma and loss (Aponte, 2002).

Some authors provided examples of how MFTs can help clients work through spiritual issues. Carlson and Erickson (2000) integrated spirituality with narrative therapy, delineating how therapists can use practices of deconstruction, externalizing conversations, exploring unique outcomes, and re-authoring personal narratives with how people's relational identity stories relate to their relationships with God. Frame (2000b) presented a spiritual genogram that clinicians may implement as a multigenerational map of family members' spiritual affiliations, experiences, and conflicts. She contended that this tool can help clients understand their families' spiritual/religious heritage and how it influences current issues with which they struggle. Hodge (2000) introduced a spiritual ecomap that delineates a family's current relationships to spiritual domains in their lives. For example, a therapist could map how a family defines and experiences spiritual areas 
such as rituals, a faith community, God/Transcendent, and the parents' spiritual tradition. Prest and Keller (1993) presented therapeutic strategies involving spiritual concepts that clinicians can apply with both traditional and nontraditional belief systems. One example is for therapists and clients to discuss how humans are manifestations of God, which promotes a positive self-concept and fits with both Eastern and Western spiritual traditions.

A few writers addressed spirituality and specific issues that may arise in therapy. For example, Knudson-Martin (2001) examined gender and spirituality in MFT, pointing out that therapists often feel confused about addressing spirituality and areas of gender and equality. In the area of marital therapy, Heller and Wood (2000) studied the influence of religious differences on couple intimacy, finding that strengths exist in both intermarried (partners religiously similar) and intramarried (partners religiously different) couples. Keoughan and Joanning (2001) presented several stages individuals and families may experience when leaving religious systems, such as Internal Questioning, Reorganization of Beliefs, Grief, and Reclamation of Spirituality (p. 6). They asserted that recognizing such stages helps therapists understand and normalize what people endure when pulling away from religious groups. Interestingly enough, not all authors appreciated how MFTs have addressed spirituality. Joanides (1996) criticized the literature in this area, contending that much of it inadequately assists MFTs in their work with spiritually oriented people. He stated that these works tend to minimize the spiritual experience in therapy and reduce the importance of discussing theological beliefs. 


\section{Ethical Issues of Addressing Spirituality in MFT}

As clinical practitioners, it is important to mention the ethical dimension of addressing spirituality in MFT or any therapeutic context. Ethics or ethical behavior, of course, comprise a significant part of therapists' work, as clinicians focus on the welfare of clients, being aware of the consequences of their behavior on both clients and clients' social systems (Haug, 1998). It seems that the ethical standards of MFTs and other clinicians have not adequately addressed the concerns that come with increased acknowledgement of spiritual issues in therapy (Frame, 2000a). In his qualitative study, Gubi (2001) related therapists' concerns about initiating prayer in session, suggesting that prayer may influence the power balance in the therapeutic relationship, as well as raise issues of spiritual inadequacy and apply pressure to comply with the therapist. One interviewee questioned, "If I'm praying with them, do I become a fellow Christian, sharing a prayer, or do I become a priest?" (p. 432). Frame's (2000a) article illustrated an example of an ethical dilemma a therapist with pastoral experience faces. A couple sought out the clinician primarily for his ministerial background, and their problems included spiritual differences. Frame (2000a) pointed out that the therapist is especially vulnerable to imposing his spiritual beliefs on his clients; therefore, it would be inappropriate for him to require that the couple subscribe to his beliefs or worship at his church. Frame (2000a) asserted that the clinician in this example must focus on his role as a family therapist, acknowledging that the role may include spiritual discussions, but

"its primary domain is psychological, not spiritual" (p. 73). Within marriage and family 
therapy and other fields, clinicians need to consider how to address spirituality with clients by clearly delineating their roles and avoiding tasks and functions reserved for clergy members - and supervisors can facilitate this process (Frame, 2000a).

\section{Spirituality in Training and Supervision-Other Fields}

Like spirituality in therapy, spirituality in training and supervision has appeared in several areas of the literature. Specifically, three mental health fields other than marriage and family therapy have addressed this issue: clinical psychology, counseling psychology, and counselor education. The following three sections will discuss the degree to which supervision and/or training programs in these fields have tackled spirituality.

Clinical Psychology. As in other fields, Brawer et al. (2002) contended that few psychologists have obtained training in the area of spirituality, even though it is a significant part of many people's lives. They cited that most clinical psychologists do not consider spiritual worldviews very important, which emerges in the literature. At the same time, Brawer et al. (2002) found that spirituality was likely to be addressed in supervision, according to 77 percent of 101 directors of clinical training at APAaccredited clinical programs within the U.S. and Canada. The researchers cautioned, however, that this statistic might be misleading, as several respondents commented that coverage of this topic was inconsistent. Participants' responses included the following statements: "it comes up periodically," "highly variable," "if appropriate," and, "only a couple of supervisors address the issue" (p. 204). In contrast, Derflinger (1997) examined 
one specific clinical psychology program housed in a religious institution. She explored how doctoral students perceived their faculty members helping them in the area of integrating psychology and spirituality. This study followed the research protocol of Sorenson (1995), who focused on a program at a different religious university. Findings indicated that graduate students in that doctoral program evaluated the faculty's level of assistance based on two latent constructs that relate to integration: (1) sense of humor; and (2) personal spirituality. These dimensions resonate with Sorenson's (1995) findings from the other institution. It seems, then, that training programs in clinical psychology are addressing spirituality to some degree. A difference also appears to exist in how programs in religious versus non-religious universities intentionally integrate spirituality into the psychology curriculum.

Counseling Psychology. In the area of counseling psychology training, three studies addressed spirituality in graduate programs. Schulte et al. (2002) surveyed 40 directors of counseling psychology programs in the U.S. that are members of the Council of Counseling Psychology Training Programs (CCPTP). They examined the degree to which spiritual issues are integrated in students' training, defining it as an issue of diversity in this field. Results suggested that these programs offer little formal course work on spiritual issues. Moreover, participants stated that spirituality was often but not always considered part of diversity, and knowledge about spirituality was not seen as important to the expertise of supervisors, therapists, and faculty members (Schulte et al., 2002). 
In a qualitative study, Gubi (2001) interviewed seven therapist trainees from British universities to investigate the potential use of Christian prayer in session. Interestingly enough, only four out of seven participants affiliated themselves with Christian denominations. After a grounded theory analysis, Gubi (2001) discovered that prayer could engage with the therapeutic process on two levels: (1) the covert level; and (2) the overt level. Participants found covert prayer (a personal prayer or moment of silence conducted by the therapist either within or outside session, often without the client's knowledge) beneficial for grounding the clinician. In this context, the trainees viewed prayer as an expression of hope and a realization of the limitation of their abilities in the therapy room. The therapists regarded overt prayer (praying aloud in session) more cautiously, contending that its use could have ethical implications (Gubi, 2001).

Within a graduate psychology program at a religious university, VanMeter, McMinn, Bissell, Kaur, and Pressley (2001) conducted an experimental design study in which they examined the use of silence in therapy for Christian clinicians. Silence has long been considered a spiritual discipline associated with the contemplative Christian tradition; therefore, the researchers aimed to determine how personal practices of spiritual disciplines could change the therapist. Findings indicated that more introverted individuals responded positively to a training program involving the disciplines of solitude and silence when compared to a group of extroverts (VanMeter et al., 2001). Again, it seems as if counseling psychology training programs differ in focus within religious universities versus non-religious universities, with religious-oriented programs consciously attempting to integrate spiritual factors. On the other hand, Gubi's (2001) 
research suggested that people, regardless of their religious affiliation, may include spiritual practices throughout the therapeutic process, but on a more personal and less institutionally driven level.

Counselor Education. One article focused on the counselor education training area. Fukuyama and Sevig (1997) delineated a new course in spiritual issues for graduate students. The authors' rationale for such a course included the need to develop a multicultural perspective, emphasizing that an awareness of spiritual concerns exists as a component of clients' worldviews and values. Fukuyama and Sevig (1997) also pointed out that most addiction recovery programs have a spiritual dimension, and many models of wellness and health incorporate spirituality. It is interesting to note that neither author works at a training program at a religious-oriented university. It appears, then, that it is possible for such programs to offer specific courses on spiritual issues, even though they are housed within state universities.

\section{Spirituality in MFT Training and Supervision}

The body of marriage and family therapy literature included several resources on addressing spirituality in supervision and training. Similar to other mental health fields, MFT works in this area have emerged only recently-a few within the past 10 years, and the majority within the last four years. Several authors (Frame, 2001; Harris, 1998; Prest \& Keller, 1993; Prest et al., 1999) discussed how MFT training programs tend to overlook spiritual issues, emphasizing that unless trainees attend programs that espouse spiritual beliefs, spirituality is rarely addressed. It is possible that many MFT graduate 
schools are unprepared to address spiritual issues, which fits with the lack of attention given to spirituality in family therapy theories. Harris (1998) advocated a broader perspective when examining the theoretical roots of MFT, challenging readers to seek spiritual explanations for the basic tenets of these theories. In structural therapy, for example, the author questioned, "Is it possible that structure is important because structure is a basic part of the spiritual dimension of humanity?" (p. 82).

Haug (1998) also accentuated the importance of therapists learning how to create space for clients to discuss spiritual issues that are important to them. To that end, the author suggested that supervisors and faculty members foster sensitivity and receptivity in their students. Haug (1998) also presented several practices that would be helpful in training: (1) Learning about different spiritual practices and rituals, as well as attaining the language used to describe them; (2) Understanding the spiritual tenets that serve as the foundation of these traditions; (3) Developing a spiritual history; and (4) Asking clients about the role and meaning of spirituality in their lives.

It would benefit therapists-in-training to discuss such issues during their graduate programs in order for them to articulate more clearly their own beliefs and how they integrate with family therapy theories (Harris, 1998; Haug, 1998; Prest et al., 1999). Prest et al. (1999) demonstrated that discussing spirituality in training is needed in their survey of 66 MFT students. Results indicated that participants valued the role of spirituality in their clients' lives, as well as their own lives. The majority of the students in the study believed that spirituality enhances clinical work. They considered religious and spiritual factors during assessment, and they integrated clients' spiritual metaphors and symbols in 
therapy. The research found, however, that "[f]ewer than half of the group have had any training regarding the intersection of clinical work, spirituality and religion, and none has received any training within the graduate programme" (Prest et al., p. 74). The authors concluded that even though the students found spirituality an important part of the therapeutic process, the trainees "often believe they do not receive adequate training or possess the necessary skills to do so" (p. 74). Given that therapists-in-training are already integrating and addressing spirituality in therapy, it seems crucial to guide and teach them how to explore this area in an ethical and professional manner.

In the area of supervision, it seems important for supervisors to help trainees explore their spiritual history so they can become more in touch with their own biases and beliefs (Harris, 1998; Haug, 1998). Frame (2001) illustrated how supervisors can integrate the spiritual genogram into the training process. She contended that students may use this tool to increase self-awareness of spiritual traditions within their family-oforigin. Supervisors can ask certain questions to help trainees understand how their spiritual history influences how they form their beliefs and practice therapy in the present:

(1) What role, if any, did religion/spirituality play in your life when you were growing up? What role does it play now?; (2) What view did/does your religious/spiritual tradition hold about gender? About ethnicity? About sexual orientation?; and (3) How does your religious/spiritual history connect with your attitudes toward working with clients' religious or spiritual issues? What new insights or concerns occur to you based on the discoveries made through the genogram? (Frame, 2001, p. 111)

Frame (2001) stated that discussing these questions with classmates and colleagues will help trainees develop the stance or attitude they will take when working with spiritually 
oriented clients. She cautioned, however, that this procedure may not be useful if trainees and/or supervisors feel reluctant to talk about spiritual concerns in supervision.

Moreover, if supervisors or educators are ill-equipped to discuss spirituality in the context of training or treatment, they may need to consult with colleagues or with clergy before incorporating the spiritual genogram (Frame, 2001).

Although it seems that many MFT programs do not typically address spirituality in the training process, Patterson et al. (2000) presented a practical method of exploring spiritual issues and how they relate to therapy. At the University of San Diego, the MFT graduate program offers a seminar on "Spiritual Issues on Family Therapy" (Patterson et al., 2000). Before they implemented this seminar, several of their students had expressed confusion about dealing with issues of spirituality at their practicum sites. The program recognized, then, that students need specific and comprehensive training in this area. Even supervisors noted instances when unprepared trainees encountered problems involving spiritual dimensions of a family system, not knowing how to integrate spirituality into the assessment and the treatment plan (Patterson et al., 2000). The course goals of this introduction to spirituality include learning how to dialogue with families and individuals about spiritual issues and discerning when to refer clients to clergy members. In addition, the material helps students become more aware of "wisdom traditions" through comparative religions material, and it identifies many of the current spiritual issues that may arise in therapy (p. 203). At the end of one course, students reported positive experiences that they felt improved their effectiveness as therapists, helping them understand how their own ideas and experiences influence how they 
perceive clients' spiritual journeys. One student explained, "I thought because I was Catholic that I understood what it meant to be Catholic. What I found out was that another person's experience with Catholicism could be vastly different from my own" (Patterson et al., 2000, p. 208). She continued to relate how assuming "a position of curiosity" helped her recognize the spiritual issues that form the bases of clients' problems (Patterson et al., 2000, p. 208).

Carlson et al. (2002) discussed the need to look at the therapists' spirituality in particular as part of MFT training. Emphasizing the importance of exploring the relational nature of therapy, they delineated a three-step process in which this issue can be addressed in supervision. The first step focuses on helping trainees "identify the spiritual preferences they have for their relationships with others" (Carlson et al., 2002, p. 226). Supervisors ask therapists to consider how they have relational concerns for clients, then they inquire how these concerns are connected to any spiritual beliefs they may have. The next step helps trainees reflect critically on how their spiritual preferences may influence their lives and the lives of their clients. A supervisor may ask, for example, "What would this way of understanding others mean to your work as a therapist? How might it contribute to your views about what is important in therapy?" (Carlson et al., 2002, p. 228). In step three, the authors draw on their narrative perspectives by encouraging supervisors to have conversations about specifics of therapists' spirituality. For example, if a trainee shares that her spiritual preference was love, a supervisor would ask her to share how she has experienced love in relationships and how those experiences have taught her about feeling compassion and care for other people. 
Along a similar vein, Bava et al. (2002) presented a conversation about spirituality among therapists at the Houston Galveston Institute, which is a postmodern training context. The authors, who were therapists-in-training, intended "to create dialogical space for multiple meanings and to honor each of our unique voices and to invite ... the reader, to reflect on and juxtapose [her/his] own experience" (Bava et al., 2002, p. 237). From a postmodern perspective, the authors delineated how they thought about and experienced spirituality as they discussed and wrote about this topic over several months. They illustrated how they constructed new meanings and gained new knowledge through collaborative conversation in training (Bava et al., 2002).

It is significant that only Prest et al.'s (1999) article presented research on spiritual issues as a dimension of MFT training. One article discussed an actual course implemented in an MFT program; the rest were simply theoretical pieces. There is no evidence that scholars specifically have examined spirituality in supervision. The lack of research in this area suggests that scholars have not explored whether or not topics in the area of spirituality are being addressed in MFT supervision, or with what frequency.

\section{Addressing Spirituality of Trainees in Supervision}

Similar to learning how to address spirituality in therapy, Stander et al. (1994), Frame (2001), and Walsh (1999) focused on the importance of therapists becoming aware of their relationship to spirituality. They contended that delving into trainees' perceptions and reactions surrounding spiritual issues will help them better understand their emotional responses in this therapeutic area. Haug (1998) and Harris (1998) also 
maintained that self-exploration and values-clarification are a part of all therapists' training. Examining spiritual issues lets both spiritually oriented and non-spiritually oriented therapists deal with their clients' spiritual values with sensitivity (Haug, 1998).

One significant period of a therapist's development is the first year in graduate school. Lee, Eppler, Kendal, and Latty (2001) described a project in which first-year MFT students wrote in a journal daily about critical incidents that "captured something important in terms of [their] professional development" (p. 53). Several themes of spirituality and self-of-therapist reflections emerged in their writings. For example, many students shared their feelings of being overwhelmed with some of their cases, describing incidents in which they felt uncertain when working with clients different from them in areas of religion, ethnicity, age, gender, marital status, etc. One therapist discussed how she felt torn between her identity of being Catholic and her identity as a therapist, especially when dealing with certain topics, including abortion and homosexuality. Like adolescents trying to figure out who they are and who they want to be, trainees face difficult personal, ethical, and spiritual dilemmas about which they often keep silent (Lee et al., 2001). It appears that supervision could serve as a setting in which trainees could articulate these dilemmas and learn how to deal with the challenges of being a therapist; however, there is currently no research that indicates the frequency with which this kind of training is occurring in MFT programs. 


\section{Supervisory Styles}

Many therapists' experiences of supervision depend on the style and personality of the supervisor. For example, if a first-year MFT would like to explore self-of-therapist issues, which could include spirituality, she/he would need to feel comfortable and safe enough to talk about such personal topics. Long et al. (1996) examined how the supervisor's personality and convictions emerge in the supervisory relationship. They described several characteristics of supervisory style, which included characteristics like hierarchical or egalitarian. They also emphasized that styles can stem from the supervisor's theoretical foundations. A structural or strategic supervisor, for instance, would maintain a clear hierarchy in supervision, as he/she would assume that problems occur in supervisory relationships when there are problematic boundaries. Supervisors from feminist, Bowenian, and Milan perspectives would advocate a collaborative and open relationship, sharing in the responsibility of case conceptualization with the therapist (Long et al., 1996). In Anderson et al.'s (2000) study of best and worst supervision experiences, trainees indicated that they did not appreciate supervisors' authoritarian stances, and they reported that they preferred an open supervisory environment that included straightforward communication that encouraged experimentation.

Ratliff, Wampler, and Morris (2000) presented a qualitative study that examined what therapists and supervisors actually face when a lack of consensus occurs. Findings illuminated a process in which supervisors made evaluations and suggestions very tentatively, and therapists did not promise to implement what the supervisors articulate. 
Ratliff et al. (2000) suggested that these interactions illustrate a mutual respect for the autonomy of both the supervisor and the therapist. Another possibility is that trainees and supervisors were trying to avoid conflict. It is interesting that this pattern resembles the open supervisory environment desired by participants in Anderson et al.'s (2000) study. Moreover, it indicates that a less hierarchical and less directive supervisory relationship may create the setting trainees need to develop their identities as therapists.

\section{Feminist Theory}

As feminist theory serves as one of the guiding theories of the present study, the following section will outline basic principles of this worldview. Focusing on the oppression of women and minority groups, feminist theory challenges the myth that the family is a safe haven, emphasizing that it is often the most intimate relationships that oppress and dominate women (Baber \& Allen, 1992). Walters, Carter, Papp, and Silverstein (1988) and Haddock, MacPhee, and Zimmerman (2001) presented feminism as an organizing framework or world view that focuses on the rules, roles, and interactions between individuals. They explained that a feminist framework strives to include the experience of women in all areas of humanity, eliminating the dominance of male-focused assumptions. In feminist theory, gender exists as a central organizing principle of relationships (Vatcher \& Bobo, 2001). Feminist-oriented scholars aim to challenge power differentials and hierarchy by addressing issues of gender, culture, and social justice in their work (Zimmerman \& Haddock, 2001). Baber and Allen (1992) delineated three types/models of feminism: (1) Feminist empiricism; (2) Feminist 
standpoint theories; and (3) Postmodern feminism. Other types of feminism have been discussed elsewhere, such as Marxist feminism, ecofeminism, radical feminism, and socialist feminism (Osmond \& Thorne, 1993). Exploring the assumptions of each of these types expands beyond the scope of this literature review. As part of the theoretical foundation of this study, the author will integrate concepts from postmodern feminism.

\section{Postmodern Feminism}

Postmodern feminism rejects the notion that one single standpoint captures women's experiences. Instead, it embraces the heterogeneity inherent in all groups, including women and ethnic minorities (Baber \& Allen, 1992). Advocating fragmentation and multiplicity, this perspective emphasizes the intersubjective meaning that people give to reality (Miller \& Wieling, 2002). Baber and Allen (1992) emphasized that "there is no woman's voice, no woman's story, but rather a multitude of voices that sometimes speak together but often must speak separately" (p. 19). What one group or individual considers oppressive may not be oppressive for another person or group; what one considers salient or meaningful may not be for others.

Postmodern feminism recognizes that differences exist among women and among men, not just between them. It also challenges prevailing assumptions of gender neutrality, questioning descriptions of the similarities of males and females (Baber \& Allen, 1992). Powerful tools of this worldview are language, discourse, and text, due to their ability to lift up certain realities while undermining others and regarding them as invisible (Miller \& Wieling, 2002). 
When dealing with spiritual issues in therapy, a clinician working with a postmodernist feminist lens may listen to clients' stories with an attitude that not one person's experience or belief defines everyone's experiences or beliefs—even if they associate themselves with the same religious organization. Likewise, supervisors from this perspective would focus on understanding trainees' spiritual views and knowledge from an open, nonjudgmental stance, recognizing that multiplicity exists among therapists' lives as well.

\section{Feminism in MFT}

Feminism emerged onto the marriage and family therapy scene with HareMustin's (1978) article in Family Process. She presented a new approach to therapyfeminist family therapy, describing it as an "orientation that considers that consequences of stereotyped sex roles and the statuses prescribed by society for females and males should be part of family therapy practice" (p. 181). Hare-Mustin (1978) pointed out how the systemic roots of MFT embraces social systems as contributing factors of behavior, which coincides with feminist ideologies. Goldner (1985) echoed these ideas, asserting that the field has been handicapped by avoiding and almost ignoring feminist scholarship and critique. Walters et al. (1988) and McGoldrick, Anderson, and Walsh (1998) expanded on these works through women's movements in MFT, such as The Women's Project in Family Therapy and the Stonehenge Conference, respectively. In their book, Walters et al. (1988) described the family not only as a system, but as a gender-based structure that exists to organize the relationships and social lives of women and men. 
Moreover, they illuminated the sexism occurring in training and practice, giving voice to women's concerns that MFT circles had not previously heard. Chaney and Piercy (1988) developed the Feminist Family Therapy Behavior Checklist (FFTBC), which is a tool for evaluating the practice of feminist family therapy skills. This measure focuses on helping MFTs deal with sex roles and power differentials, as well as expanding the therapeutic context to look at the influence of institutional and social forces on the family system. Danoski, Penn, Carlson, and Hecker (1998) explored the practice of feminist family therapy within the MFT field. After surveying American Association for Marital and Family Therapy (AAMFT) members, they found that MFTs practice with feminist ideals, yet they hesitate to call themselves feminists. Although this disinclination continues within the field, it seems that scholars feel more comfortable addressing issues of gender, power, and oppression in the literature.

\section{Feminism in MFT Training}

In marriage and family therapy programs across the U.S. and Canada, supervisors and faculty members appear to integrate feminist principles to varying degrees. Although only a few articles address how to apply feminism to MFT training, they provide practical examples of how programs help students learn about gender, power, equity, and hierarchy in the therapeutic context. Within the literature addressing marriage and family therapy curricula, two articles explore different approaches to the study of gender. In their research, Filkowski, Storm, York, and Brandon (2001) compared two COAMFTE accredited programs: one that provides a separate course on gender, and one that 
integrates gender issues throughout the entire curriculum. Findings suggested that students from the integrated program see colleagues as implementing gender principles to a larger degree than trainees who have a separate gender class. On the other hand, results indicated that students with the gender course tend to agree with feminist principles more than trainees from the other program. Filkowski et al. (2001) contended, however, that students from both programs seem to be learning about gender and applying these concepts to the therapeutic arena. The second article (Zimmerman \& Haddock, 2001) illustrated how a MFT program "weaves" feminist principles throughout all aspects of training: supervision, class discussions and homework, and research. They focus on promoting ideas of social justice by working from four assumptions: (1) Consistency of process and content; (2) Atmosphere of humility; (3) Attention to theory and application; and (4) Attention to the interlocking nature of gender and culture (pp. 5-6). Moreover, they teach first-year students core family therapy theories using a feminist lens, which encourages trainees to consider issues of gender, hierarchy, power, and equity in both modern and postmodern ideologies.

\section{Training Tools in Feminist Family Therapy}

Two measures emerged in the literature that educators/supervisors can use as training tools. First, Chaney and Piercy (1988) suggested that supervisors implement the FFTBC instrument to include feminist interventions into trainees' foundation of family therapy techniques. After educators/supervisors introduce the FFTBC, they can use the checklist to record the degree to which therapists actually employ these skills. Another 
measure supervisors could apply to the training process is the Power Equity Guide (Haddock et al., 2000). This instrument teaches students to translate their comprehension of feminist principles into specific therapeutic behaviors and techniques. The authors emphasize that educators/supervisors need to teach feminist family therapy on personal and practical, as well as theoretical, levels. One method of illustrating feminist principles in a personal and practical manner is through the supervisory relationship. Haddock et al. (2000) asserted that " $[\mathrm{t}] \mathrm{he}$ most important factor in creating an isomorphic training process is the reduction of hierarchy in the supervisory-trainee relationship" (p. 156). Moreover, the authors contended that supervisors need to encourage trainees to develop their personal style of integrating feminist principles into their chosen theoretical orientation. It appears, then, that maintaining an open, collaborative, non-hierarchical supervisory relationship models the very ideologies that feminist theory espouses.

\section{Feminist Family Therapy Supervision}

Three fairly recent works addressed supervision from a specifically feminist family therapy framework. First, Prouty (2001) presented a qualitative study of 16 participants describing their therapist-supervisor relationship, focusing on what was the core, meaningful part of the experience. The researcher interviewed AAMFT-approved supervisors who identified themselves as feminists, and she also recruited one therapist who was working with each of the supervisors. Findings revealed that feminist supervisors explained that the practice of supervision functioned as an extension of who they were-feminists. Furthermore, a strong emphasis emerged on the importance of the 
supervisory relationship, discussing the significance of encouraging respect, being committed and available to therapists, discussing the relationship itself, and challenging trainees in a supportive and stimulating manner.

In another article from the same study, Prouty et al. (2001) found that three supervision methods emerged through the analysis. The first method, the supervisortherapist contract, discussed the importance of eliciting training goals at the outset of the supervisory relationship. It also addressed the practice of mutual evaluation, as well as clarifying therapists' responsibilities. The second method was collaborative supervision, whose techniques include encouraging mutual feedback, providing options instead of directives to therapists, and applying multiple perspectives. Feminist family therapists do not typically discuss hierarchical supervision methods, yet it emerged as the third method in the study. In general, supervision was collaborative. Hierarchical approaches occurred when clients were unsafe (e.g., violent situations), or when the therapeutic situation called for abilities beyond the trainee's level of experience. At times, therapists themselves would request hierarchical supervision (Prouty et al., 2001).

An additional work in this area is Wheeler, Avis, Miller, and Chaney's (1989) feminist model of training and supervision. Their model aimed to complement existing models of marriage and family therapy, expanding on skills that are specifically feminist in their focus and intent. They delineated two categories of skills for feminist family therapists: perpetual/conceptual skills and executive skills. The first category encouraged a shift from a purely interpersonal view to a political perspective-one that recognizes power and powerlessness in relationships. The "executive skills" category focused on 
cultivating a collaborative relationship between therapist and client(s); it also teaches the therapist to act in an active and competent manner.

\section{Theory of Power-Foucault}

The French philosopher, Michel Foucault, published works within a 30-year period that have had a widespread influence within philosophy and the humanities (Flaskas \& Humphreys, 1993). Operating from a postmodern perspective, Foucault maintained that no objective facts exist about a person's nature (White \& Epston, 1990). He believed instead that the social context grants a "truth status" to constructed norms or ideas (White \& Epston, 1990, p. 19). Although relatively unfamiliar within the marriage and family therapy field, authors such as Michael White have integrated Foucault's ideas within the theory of narrative therapy (Flaskas \& Humphreys, 1993; White \& Epston, 1990). Foucault's ideas provide a framework for interpreting the clinician's and the client's "contextualized subjectivity," as well as the dynamics of therapeutic process and interaction (Keenan, 2001, p. 211). The core Foucauldian concept relevant to this study is power. Foucault contended that one cannot see power in and of itself. Instead, one can perceive the effects of power in everyday interactions, in the systemic structure of personal relationships, and in how thinking and knowledge are generated (Flaskas \& Humphreys, 1993). In a conference at the University of Tokyo, Foucault (1978) explained how he viewed power contextually within its environment:

"I do not ask, 'Where does power come from, where is it going?' but rather, 'In what way does it happen and how does it happen, what are all the relations of power, how can one describe certain of the principle relations of power which are exercised in our society."' (p. 127) 
Foucault (1978) illustrated the relationship between power and subjective truth through an example of a Christian practice: confession. He stated that as a Christian individual confesses to a pastor and examines his/her conscience, it somehow produces a truth that neither the person nor his/her pastor knew beforehand. Subjective truth, then, emerges through an interaction; if the interaction did not occur, this form of truth would not have been attained (Foucault, 1978). Foucault also explained that power causes a "normalizing judgment" to occur as power interactions construct a hierarchical system of values that define both averages and boundaries of external limits (Keenan, 2001). For example, Keenan (2001) discussed how the mental health field has constructed The Diagnostic and Statistical Manual of Mental Disorders, Fourth Edition (DSM-IV, American Psychiatric Association, 1994) that clinicians in various disciplines use to classify behaviors and symptoms for diagnosis, communication, and financial reimbursement. This categorization system articulates what is considered "abnormal" and "unhealthy" within mental health, which both marginalizes and oppresses people who fall into these categories, establishing a hierarchy between people who are diagnosed and the powerful individuals who do the diagnosing (Keenan, 2001). Religion, too, appears as one of the practices by which society categorizes, marginalizes, and validates the history, institutions, and experiences of the human race (Strenski, 1998).

In the area of religion and power, Foucault (1978) outlined the previously mentioned idea of the pastor/leader that serves as a shepherd to his flock, contending that it comes from countries such as Egypt, Mesopotamia, Assyria, and in Hebrew society. This concept serves as a powerful political, moral, religious, and social theme that is 
absolutely fundamental to the culture. It also stems from a process of individualistic power, for "the shepherd [berger] must ensure the salvation of the flock, but he must ensure the salvation of each individual" (Foucault, 1978, p. 123). These themes both free and limit humans, for each person has the responsibility to seek her/his own salvation; however, she/he can attain this salvation only through an acceptance of the authority of another person (the pastor/shepherd) (Foucault, 1978). Addressing both power and religious issues throughout his career indicates that Foucault recognized the degree to which these areas are intertwined. Given that power is everywhere, it appears that supervision is a prime setting for issues of power to emerge-especially with the theme of spirituality.

\section{Foucault and Feminism}

In an interaction that scholars described as alternately complementary and contradictory, some feminists hesitated to collaborate with Foucauldian thought, while others contended that Foucault and feminism can be allies (Carrette, 1999; McLaren, 1997). MacLeod and Durrheim (2002) also maintained that feminist circles have received Foucault's ideas "with varying degrees of enthusiasm" (p. 41). Indeed, the bulk of Foucault's work that seemed to collaborate with feminist thought is the pervasive nature of power and the political (McLaren, 1997). According to Foucault, power "is not exercised from the exterior; it is not possessed by an individual, class or group, nor is it centralized in the law, economy or the state... . it is immanent to everyday relationships" (cited in MacLeod \& Durrheim, 2002, p. 43). Liberal feminists would find this 
description of power in accord with their belief that what is personal is also political. Conversely, radical feminists would tend to criticize Foucault's ideas, as he undercuts the notion of group politics. At the same time, Foucault recognized several times in his works that even though power is pervasive, it is not equally distributed (McLaren, 1997). Although no one individual or group holds power from a central position, it does not mean that groups and people are positioned equally within society or that global domination cannot be addressed. With this perspective, both types of feminists can acknowledge a patriarchal structure, recognizing that male domination occurs in almost all cultures (MacLeod \& Durrheim, 2002).

\section{Power/Gender/Hierarchy Issues in Supervision}

One important aspect of the supervisory relationship is issues of power/gender/hierarchy. Given both feminist family therapy and Foucault's ideas about power, it seems that supervision is a prime situation in which these issues can emerge. Ault-Riché (1988) discussed gender and power within training and supervision, describing the experiences of female students and supervisors. As trainees, women often struggle with acting assertively within therapy, preferring the relationship-oriented focus to implementing tasks in a directive manner. Ault-Riché (1988) also contended that new female therapists struggle with fearing men's power, as well as sex-role expectations placed on them by supervisors, educators, clients, colleagues, and society as a whole. She called upon supervisors, especially women, to model assertiveness and to challenge these sex-role stereotypes in practice. 
Supervisors also may grapple with attitudes toward females in authority positions (Ault-Riché, 1988). Institutions might see female supervisors as not having enough power, and women themselves could minimize their talents and become more "quiet" and "feminine" to avoid challenging the status quo. Indeed, women often find themselves in a double-bind, for if they present themselves as nurturing, they risk not being taken seriously. On the other hand, if they seem too assertive and task-oriented, they may be seen as dangerous. Ault-Riché (1988) encourages female supervisors "to act with firm benevolence," which means to establish themselves as authoritative, but not destructive (p. 187).

McDaniel et al. (1995) focused on male trainees' experiences with a female supervisor. Emphasizing that women and men encounter different developmental tasks related to their gender and socialization experiences, the authors pointed out that the gender of the supervisor also may influence how these tasks are addressed. They .challenged women who work as supervisors to recognize expectations and stereotypes trainees could bring to supervision; for example, they may expect to learn more relationship skills and fewer directive interventions from women than they would with male supervisors. It is interesting to note that male therapists do not fit the gender stereotype, with their desire to care for others overtly and deal comfortably with others' emotions. McDaniel et al. (1995) found that the male trainees often questioned the degree to which their problems in therapy related to their socialization as men. If they did not have children, they felt uncomfortable treating them in therapy. They also contended that the females in their lives recognized power dynamics in relationships more easily than 
they did. The female supervisor experienced challenges in several areas, including a heightened need to demonstrate credibility and leadership early in the supervisory process. Moreover, she found that leadership emerged as a more important issue than usual, feeling the need to supervise in a directive manner instead of just making suggestions (McDaniel et al., 1995). It is possible that many female supervisors become more intentional in establishing their leadership, given the assumptions and stereotypes they face when they hold positions of authority.

McHale and Carr (1998) and Moorhouse and Carr (2002) further illuminated how gender affects conversational behavior between supervisors and trainees. McHale and Carr (1998) examined 40 episodes of supervision discourse, based on four types of supervisory systems: (1) male supervisor/male trainee; (2) male supervisor/female trainee; (3) female supervisor/male trainee; and (4) female supervisor/female trainee. Contrary to sex-role stereotypes, results suggested that female supervisors presented a directive supervision style more frequently than male supervisors. Findings also indicated that supervisor/trainee pairs of the same gender (male/male, female/female) demonstrated a collaborative systemic supervision style. McHale and Carr (1998) speculated that women and men who chose to pursue family therapy as a career may not conform to stereotypic communication styles. Moreover, they suggested that female supervisors may respond to training by developing a directive supervisory style, while men acquire a collaborative supervisory style.

In Moorhouse and Carr's (2002) more recent work, the researchers explored conversational behavior in live supervision between different gender-paired therapists 
and supervisors. They also found that their results did not adhere to gender stereotypes. Collaborative behavior occurred more frequently in male supervisor/male therapist interactions, and it happened the least when male supervisors worked with female therapists. Moorhouse and Carr (2002) discovered that therapists tended to behave more collaboratively and were less directive with clients when they came from male therapist/female supervisor systems. Again, the researchers postulated that therapists and supervisors may not fit gender stereotypes in their conversational behavior. Another influencing factor in both of these studies may be that the researchers conducted the studies in family therapy training programs in Ireland so their results may not apply to supervision experiences in the U.S.

\section{Addressing Therapist/Supervisor Gender, Spirituality in Supervision and Supervisory Styles at MFT Training Programs}

It appears that examining therapist/supervisor gender, spirituality in supervision, and supervisory styles in training programs are largely unexplored areas. As noted previously, both gender and spirituality are important issues in the MFT field, and supervision serves as a significant part of a therapist's growth and development. It would seem important, then, to examine how the supervision process differs with gender differences in supervisor/therapist pairs.

Keenan (2001), who wrote from a social work profession, explained that supervision is an environment in which Foucault's concept of power emerges. She contended that supervision "serves as a way to create and maintain a . . knowledge base as the authority of the supervisor exerts power in transmitting some knowledge while 
screening out other knowledge" (p. 212). In supervision, female and male supervisors communicate their knowledge to trainees through interactions within the supervisory relationship—whether through directive or collaborative styles. A process of normalizing judgment then occurs when the supervisor observes the therapist's work through several lenses, including the code of ethics, her/his theoretical background, the training program, past experiences, and her/his culture/ethnicity/race, etc. (Keenan, 2001). Both gender and supervisory styles also exist as two of these lenses, which mean that working within different contexts would influence the supervisory process.

Foucault (1978) contended that complex issues of power and hierarchy reside within all relationships—especially those with clear power differentials. In addition, feminist theory maintains that gender, power, and hierarchy issues exist as an inherent part of the social structure (Vatcher \& Bogo, 2001; Zimmerman \& Haddock, 2001). Supervisory style also emerges as an area that reflects such issues. It seems, therefore, that contextual differences such as gender and supervisory style would not only affect interactions within supervision, but also influence the frequency with which spiritual issues are discussed between the therapist and the supervisor.

\section{Hypotheses}

In this study, the variables "sex of therapist" and "sex of supervisor" are used in the hypotheses instead of "gender of therapist" and "gender of supervisor." Although gender is the overarching construct that this study is exploring, it is actually the variable of biological sex (female/male) that is considered. 
This research examined the following hypotheses:

Hypothesis 1a: There will be a relationship between the sex of the therapist and ratings of supervisory style.

Hypothesis $1 \mathrm{~b}$ : There will be a relationship between sex of the therapist and the frequency of spiritual issues addressed in supervision.

Hypothesis 2a: There will be a relationship between the sex of the supervisor and ratings of supervisory style.

Hypothesis $2 \mathrm{~b}$ : There will be a relationship between the sex of the supervisor and the frequency of spiritual issues addressed in supervision.

Hypothesis 3a: There will be an interaction effect between the sex of the therapist and sex of the supervisor on ratings of supervisory style.

Hypothesis $3 b$ : There will be an interaction effect between the sex of the therapist and sex of the supervisor on the frequency of spiritual issues addressed in supervision.

Hypothesis 4: A relationship will emerge between supervisory style and the frequency of spiritual issues addressed in supervision. 


\section{CHAPTER III METHODS}

Were there worlds beyond which they could never touch, or did all that is possible enter their consciousness? They could not tell .... Perhaps life is a mystery, not a muddle; they could not tell. Perhaps the hundred Indias which fuss and squabble so tiresomely are one, and the universe they mirror is one.

-E. M. Forster, Passage to India (p. 293)

The methodology of this study implemented a positivistic framework in exploring spirituality in MFT training. It also assumed a feminist perspective, which influenced both the theoretical underpinnings and the research methodology. Feminism is a perspective or worldview, not a research method. It focuses on multiplicity and diversity in research (Avis \& Turner, 1996). Moreover, it "is characterized by its focus on the interaction of gender and power" (Avis \& Turner, 1996, p. 153). Given that this study emphasized gender relations within supervision, as well as power dynamics in perceptions of supervisory styles, it fit within the lens of feminist scholarship. In addition, spirituality emerges as a marginalized topic in the supervision process, which coincides with feminism's interests in "multiplicity, inclusivity, and plurality of voices and methods" (Avis \& Turner, 1996, p. 152).

This study focused on new areas within the study of gender, spirituality, and supervision. It is exploratory, and it served as a foundation for future, in-depth analyses. The researcher took all possible steps to adhere to a feminist perspective, given the limitations of positivistic research (Avis \& Turner, 1996). It was a priority to keep the relationships between the feminist researcher and the participants "at a minimum, highly 
respectful, open, and nonexploitive" (Avis \& Turner, 1996, p. 154). One limitation of a positivistic framework is the hierarchy inherent in the researcher-participant relationship. In an attempt to lessen the hierarchy, the researcher visited the research sites, and she made herself available for questions and explanations (Avis \& Turner, 1996).

\section{Sample}

The sample consisted of masters and doctoral students from 12 COAMFTE accredited MFT programs. Given that the study explored dimensions of the supervisory relationship, participants had to be enrolled in the programs at least one academic year to increase the probability that they had received supervision from at least two faculty supervisors. The researcher gathered data from 153 participants. Demographic information is available in Table 3.1. Most students were able to rate two supervisors; however, a few had received supervision from only one faculty member. Some of the students had been supervised by only males or only females; therefore, they completed the measures for two supervisors of the same sex. Table 3.2 contains the distribution of the sex of supervisors. Supervisor \#1 was male for 138 students and was female for nine participants. One hundred thirty-nine students rated females for supervisor \#2, and eight participants rated males.

Four groups were represented in the study: (1) female therapists rating female supervisors; (2) female therapists rating male supervisors; (3) male therapists rating female supervisors; and (4) male therapists rating male supervisors. The group sizes varied, based on whether or not each participant had sufficient missing data to exclude 
their ratings of supervisors. The therapist-supervisor pairings also varied based on the number and sex of supervisors who were rated.

Participants were recruited from MFT programs in both religious universities and institutions not affiliated with a religious group. The researcher assumed that recruiting participants from both types of universities would provide greater diversity in responses, especially when the constructs of interest were spirituality, gender, and supervisory style in supervision. One study found that counseling psychology training programs within religious universities attend to spiritual issues more frequently than programs in nonreligious universities (Kelly, 1994). As this study recruited students from 12 universities, there was also a lot of diversity in the type of institution in which each MFT program was housed. Eight of the universities were private institutions, and four were public. Five of the private universities were affiliated with a religious organization.

The researcher visited the following universities to gather data: (1) Abilene Christian University; (2) Kansas State University; (3) University of San Diego; (4) Alliant International University; (5) Loma Linda University; (6) St. Mary’s University; (7) Purdue University; (8) Colorado State University; and (9) Texas Tech University. The majority of participants $(\underline{n}=148)$ were recruited during these visits. A few students $(\underline{n}=$ 5) were enlisted from the University of Georgia, Brigham Young University, and Auburn University via mail or through personal contact when students were visiting Texas Tech University. Three of the universities are in the southwestern United States, three on the west coast, three in the western region, one in the Midwest, and two in the Southeast. The 
geographic diversity, as well as the inclusion of both private and public universities, increased the probability of a wider range of responses.

\section{Recruitment Process}

The researcher contacted the targeted programs through personal and professional associates who were faculty members at these universities. The procedure followed a type of nonprobability sampling process called "[j]udgmental, purposive, or expert sampling" (Nelson, 1996, p. 455). This process focuses on a particular group instead of an entire population (Nelson, 1996). For this study, it was not feasible to try to access MFT trainees in all COAMFTE accredited graduate programs; therefore, the researcher contacted people known to her who allowed her to collect data from their students. These students were a group who were purposely selected, given their availability and the researcher's access to their MFT programs. The researcher is aware that nonprobability sampling introduces bias into the sample and increases sampling error (McCready, 1996).

\section{Procedures}

In January and February of 2003, the researcher wrote letters to professors at fourteen MFT programs (not including Texas Tech University). She indicated that she would follow-up the letter with an e-mail. Through e-mail, nine of the individuals responded and invited her to visit and collect data from students in their programs. After discussion with the contact person at the University of Georgia, it was decided that the researcher would mail the packets of measures, instead of visiting the campus. As 
previously mentioned, a few MFT masters students from Brigham Young University and Auburn University visited Texas Tech University during the data collection process; therefore, the researcher recruited these students individually. Overall, actual data collection lasted from February of 2003 through May of 2003. Only one MFT program required that the researcher submit a separate Internal Review Board (IRB) proposal for its university requirement to collect data from their students.

When the researcher visited the campuses of these MFT programs, she went to classes and/or internal practicum sites (e.g., held at on-site clinics). In a few instances, the program requested that she meet with students at a scheduled time outside of class. During these meetings, students were asked to participate in a study designed to examine the therapist/supervisee's perspective regarding spiritual issues in supervision and supervisory style. Any students who did not want to participate in the study (or who did not qualify for the study) left the room for the allotted time frame. Due to the personal and sensitive nature of the variables, participants were assured that the information would not be disclosed to any members of the department. Although participants signed their names on the informed consent sheets, these forms were kept separately from the measures they completed. Participants were identified on the surveys only by identification numbers that were not connected with their names. All collected data were stored in a locked area. At the end of the study, each program director will receive a summary of the findings that provides no information by which participants can be identified. 
The informed consent form was distributed and explained. After participants signed the informed consent, they were given a demographics questionnaire, two copies of the Spiritual Issues in Supervision Scale (SISS), two copies of the Supervisory Styles Index (SSI), and one feedback form. Participants were asked to complete the demographic questionnaire first. They then were requested to complete one copy of the SISS and one copy of the SSI for one female, full-time/part-time/adjunct faculty supervisor they had during their time at their current program. After they had completed these measures, they were asked to fill out one SISS and one SSI for one male, fulltime/part-time/adjunct faculty member that they had for supervision in their current program. The measures regarding the female supervisor were printed on a color of paper different from the set of measures applied to the male supervisor. If they had not had a female, full-time/part-time/adjunct faculty supervisor, they were given two sets of the measures focusing on the male supervisor. Likewise, if they had not had supervision with a male, full-time/part-time/adjunct faculty member, they were given two sets of the measures applied to the female supervisor. If they had received supervision from only one person, they completed the measures for one supervisor. The average time participants took to complete the survey packet was approximately 30 minutes.

\section{Variables of Interest}

Four main variables were examined: sex of the therapist, sex of the supervisor, supervisory style, and frequency of spiritual issues addressed in supervision. Chapters I and II discussed these variables. 


\section{$\underline{\text { Measures }}$}

\section{Demographic Questionnaire}

The questionnaire was designed by the researcher to collect data on several demographic variables (see Appendix A). These variables range from information such as age, gender, and ethnicity, to questions asking participants about the degree to which spiritual issues are addressed in the classroom and in supervision. Once again, Table 3.1 presents the demographic characteristics for all respondents. The following list identifies all variables: (1) age, (2) gender, (3) ethnicity, (4) current relationship status, (5) student status (e.g., second-year master's, third-year doctoral), (6) therapist theoretical orientation, (7) male supervisor theoretical orientation, (8) female supervisor theoretical orientation, (9) self-description as a feminist family therapist, (10) number of faculty supervisors the therapist has had (including the number who have been female or male), (11) self-description as a spiritually minded person, (12) percentage of time spiritual issues attended to in therapy (by the therapist), (13) percentage of time spiritual issues addressed in the classroom, (14) percentage of time spiritual issues attended to in supervision, (15) religious organization, and (16) participation in religious activities. The demographic questionnaire also includes an open-ended question asking participants how they define spirituality for themselves. This query provided data for future research on how MFT students conceptualize spirituality. 


\section{Supervisory Styles Index (SSD)}

Long, Lawless, and Dotson (1996) developed the SSI (see Appendix B) to examine supervisory style. The authors defined supervisory style as the manner in which the personality characteristics, beliefs, and principles of the supervisor emerge through the supervisory relationship. Grounded in feminist theory, the researchers developed this instrument to focus on the "interplay between supervisory style and the influence of sex and gender" (Long et al., 1996, p. 589). Contending that many previous works presented a male perspective on this topic, Long et al. (1996) focused on several factors of the supervisory relationship that would characterize a feminist approach to supervision. Specifically, they recognized three sets of complementary supervisory styles that were present in the literature addressing a feminist approach to training and therapy: (1) Affiliative/Authoritative; (2) Directive/Non-directive; (3) Self-disclosing/Non-selfdisclosing. Long et al. (1996) defined the affiliative style as a collaborative style that encourages egalitarian relationships, and they stated that an authoritative style emphasizes boundaries between the therapist and supervisor. With a directive style, the supervisor holds the expert position as she/he directs the therapist in what to do with cases. In a non-directive style the supervisor is not in the expert position, recognizing the supervisee's competence and unique perspective in therapy. A self-disclosing style supports the connection between supervisor and therapist, highlighting the commonalities of their experience. On the other end of the continuum, a supervisor with a non-selfdisclosing style does not disclose professional and/or personal information. 
The SSI consists of three subscales targeting the three sets of behavioral statements that can be used to characterize the style of the supervisor. The items within each subscale are comprised of statements that could describe the behavior of a specific supervisor (e.g., "The supervisor develops the final intervention to be used in a session"). On the SSI, participants rated supervisors based on a Likert-type scale, with a range of 1 to $4(1=$ Agree, 4 = Disagree $)$. Items within each of the subscales (Affiliative/Authoritative, Non-directive/Directive, Self-disclosing/Non-self-disclosing) were totaled to attain a final score that indicated the therapist's perception of the supervisor's preferred style for each subscale. Long et al. (1996) emphasized that the dimensions of supervisory style assessed by the SSI are not exhaustive; instead, they serve as a starting place from which to examine supervisory style, which coincides with the exploratory nature of this study. The authors also pointed out that they do not intend to identify one style as more successful than another style; rather, they expect that some supervisory styles may work more effectively in some situations than in others.

Long et al. (1996) tested their 19-item measure using 52 trainees in COAMFTE accredited doctoral programs who rated 182 supervisors. They then aggregated their data to increase reliability, which produced 52 supervisor ratings. Internal reliability was determined using Cronbach's alpha. Based on this analysis, the researchers deleted one item from each of two subscales. The final internal reliability coefficients attained were .79 for the Affiliative/Authoritative scale, .78 for the Non-Directive/Directive scale, and .80 for the Self-Disclosing/Non-Self-Disclosing scale. 
Reeves, Culbreth, and Greene (1997) examined the supervisory styles of substance abuse counselor supervisors using the SSI in addition to the Supervisory Styles Inventory (Friedlander \& Ward, 1984). The researchers found that these supervisors tended to focus on the relationship between supervisor and counselor, and they stated that both measures demonstrate similar content. Reeves et al. (1997) explained that the instruments "are similar in focus. In other words, each instrument does measure the degree of relationship orientation in supervisory style" (p. 80). The authors concluded, therefore, that the measures correlate in how they indicate whether or not a supervisor demonstrates a relationship-focused style. At the same time, the researchers cautioned that the correlation should be considered preliminary until further validity studies of the SSI have been performed.

\section{Spiritual Issues in Supervision Scale (SISS)}

The SISS (see Appendix C) was created by the researcher specifically for this study. Each item focuses on an area that may be addressed in supervision (e.g., assessment, marriage/divorce, culture, ethical issues). Participants rate each item using a Likert-type scale ranging from 1 to $5(1=$ Spiritual issues are never addressed; $3=$ Spiritual issues are occasionally addressed; 5 = Spiritual issues are frequently addressed). The items were reviewed for content validity by a panel $(\underline{n}=7)$ of two full-time faculty members, one adjunct faculty member, and four Ph.D. students in a COAMFTE accredited MFT program at a state university in the southwestern United States. The items were also reviewed by a one faculty member in an accredited MFT program at a 
private religious university in the same region. Two of the reviewers had researched spiritual and religious issues. Other reviewers were very knowledgeable about this area. Many also had experienced supervision in both religious and non-religious institutions, which helped them assess the items from a broader training base.

SISS Pilot Study. Participants for a pilot study of the SISS were recruited through a convenience, nonprobability sampling method (Nelson, 1996). The first author contacted mental health professionals around the country representing various disciplines who either were currently receiving supervision or had recently received supervision from professionals in their fields or programs. This process occurred via e-mail and faceto-face contact over a four-week period in January and February, 2003. Out of approximately 75 people contacted, 51 individuals completed the measure, which suggests a response rate of 68 percent. The majority of respondents $(\underline{n}=47 ; 92 \%)$ graduated from or were attending COAMFTE accredited Master's and Doctoral programs at the time of the study. The remaining participants $(\underline{n}=4)$ had received graduate training from educational psychology programs; however, all participants either had taken a family therapy class, or they had been supervised by an AAMFT approved supervisor at some point in their training.

The researcher conducted an exploratory factor analysis on the data, as there was no hypothesis about the number or nature of the factors measured by the SISS and the sample size was small. A Principal Component Analysis (PCA) was selected as the method of factor analysis. After choosing eigenvalues greater than one as the criterion for determining the number of factors, the researcher used varimax rotation to rotate the 
factors. Factor loadings of .33 or higher were allowed. As evidenced by the KaiserMeyer-Okin measure of sampling adequacy (.716), the data were able to be factored. In addition, Barlett's Test of Sphericity was significant at the .001 level, indicating that the data were acceptable for factor analysis.

The results of the PCA revealed seven underlying factors for the SISS, with the seven factors extracted accounting for 72.7 percent of the sample variance. Six items in the SISS had their highest factor loadings on the first factor. Likewise, the second and fourth factors had six items that loaded highest on them. The remaining four factors all had three items that loaded highest on each of them. The internal consistency of the SISS as a whole and on each of the seven subscales was examined. Analysis of the internal consistency for the overall scale produced a Cronbach's alpha of .94 . The reliability coefficients (Cronbach's alpha) for each of the seven subscales were also found within an acceptable range: .87 for Scale One; .84 for Scale Two; .89 for Scale Three; .80 for Scale Four; .87 for Scale Five; .79 for Scale Six; and .80 for Scale Seven.

The final structure of the entire instrument included seven scales. An examination of the six items loading on the first factor suggested that it has to do with "Gender and Identity Issues." The six items loading on the second factor appeared to relate to "Acceptance Issues." The third factor, which consisted of three items, seemed to be associated with "Family Role Issues." The six items comprising Factor 4 appeared to cluster around the theme of "Morality and Loss Issues." The common thread tying together the three items on the fifth factor was "Diversity Issues." The sixth factor, with 
its three items, seemed to have to do with "Value of Life Issues." The seventh and final factor seemed to be related to "Supervisory Process Issues."

Although an analysis of the measure produced loadings on all seven factors, Factor 1 accounted for 39.05 percent of the variance, whereas the other six factors each represented less than 10 percent. This finding suggested that the scale is a unidimensional measure that focuses on different aspects of spirituality. Indeed, spirituality is a construct influenced by many things. A definition of spirituality appears on the measure as "an overarching construct that includes a personal journey of transcendent beliefs and a sense of connection with other people, experienced either within or outside of formal religious structures." The researcher developed this definition by reviewing multiple descriptions of spirituality as conceptualized by mental health researchers (Brawer et al., 2002; Carlson \& Erickson, 2000; Kurtz, 1999; Miller, 1999; Miller \& Thoresen, 1999; Schulte et al., 2002; Walsh, 1999). Even though the researcher included this definition on the SISS as a reference for respondents, it did not guarantee that they did not interpret spirituality differently, given their varied experiences and viewpoints. Overall, it is challenging to find words that apply universally to naming all factors generated by the analysis of the SISS. The factor names that the researcher chose, therefore, could be seen only as generalizations, not definable constructs.

In addition to the difficulty of making spirituality a measurable construct, other limitations may have affected the results of the pilot study of the SISS. An important issue when conducting factor analysis is sample size. Tinsley and Tinsley (1987) suggested that a ratio of 5-10 participants per item is an acceptable sample size for factor 
analysis. In this study, only 51 individuals responded, and the SISS had 30 items. At the very least, it would be important to assess the measure's psychometric properties with a sample of 150 individuals. A convenience, nonprobability sampling method also has its drawbacks. Although it tends to produce a higher response rate than other methods, a sample bias can become compounded because participants tend to come from a similar type or group of people (Nelson, 1996). This bias, therefore, could have produced more favorable results in this developmental analysis of the SISS.

\section{Design}

This study incorporated a correlational design. This type of design functions well in exploratory research, designed to examine a diverse array of preliminary hypotheses (Campbell \& Stanley, 1963). It examines the extent to which variables of interest covary, or "co-relate" (Snyder \& Mangrum, 1996), and it produces results that can be considered associative (Nelson, 1996). Correlational designs are sometimes considered preexperimental designs, as they can serve as preliminary pilot studies to experimental research that focuses on cause-and-effect relationships (Patten, 2000). The research analyses, in turn, determine whether or not these variables are significantly correlated with one another. 
Table 3.1

Demographics for All Respondents $(\underline{n}=153)$

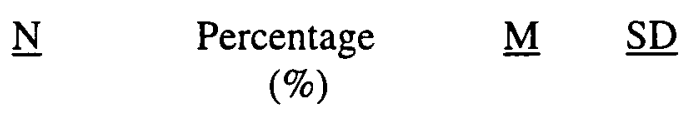

University

$\begin{array}{lrr}\text { Abilene Christian University } & 13 & 8.5 \\ \text { University of Georgia } & 2 & 1.3 \\ \text { Kansas State University } & 18 & 11.8 \\ \text { University of San Diego } & 3 & 2.0 \\ \text { Alliant International University } & 25 & 16.3 \\ \text { Loma Linda University } & 37 & 24.2 \\ \text { St. Mary's University } & 13 & 8.5 \\ \text { Purdue University } & 14 & 9.2 \\ \text { Colorado State University } & 11 & 7.2 \\ \text { Texas Tech University } & 14 & 9.2 \\ \text { Brigham Young University } & 2 & 1.3 \\ \text { Auburn University } & 1 & 1.7\end{array}$

Age

Sex

Female

Male

Ethnicity

Native American/Alaska

Native

6

3.9

Asian/Pacific Islander

12

African-American (Black)

8

7.8

Latino/a

18

5.2

European-American

Other

98

11.8

4 . 2.6

Middle-Eastern

4

2.6

African

4

2.6

3

2.0 
Table 3.1

(Continued)

$\underline{N} \quad$ Percentage $\quad \underline{M} \quad \underline{\text { SD }}$

(\%)

Current Relationship Status

Single

Cohabiting, no children

$\begin{array}{rc}52 & 34.0 \\ 9 & 5.9 \\ 0 & 0 \\ 26 & 17.0 \\ 43 & 28.1 \\ 5 & 3.3 \\ 12 & 7.8 \\ 6 & 3.9\end{array}$

Cohabiting, children

Married, no children

Married, with children

Separated

7.8

Divorced

Other

3.9

Student status

First-year masters

Second-year masters

Third and higher masters

44.4

First-year doctoral

5.2

Second-year doctoral

9.8

Third-year doctoral

Fourth-year doctoral

Fifth-year and higher doctoral

Other

Epistemological Orientation of Self

Modern

Postmodern

Other

Missing

Feminist Family Therapist

Yes

No

Missing
92

58

3
60.1

37.9

2.0 
Table 3.1

(Continued)

$\underline{\mathrm{N}} \quad$ Percentage $\quad \underline{\mathrm{M}} \quad \underline{\mathrm{SD}}$

(\%)

Perceived epistemology of

supervisor \#1 (usually male)

Modern

Postmodern

Other

Not applicable

Missing

Perceived epistemology of

supervisor \#2 (usually female)

Modern

Missing

Number of supervisors

Number of female supervisors

Number of male supervisors

Perceived self as a

spiritually minded person

Yes

No

Missing

Percentage of time self attends

to spirituality in therapy

( $0 \%$ to $100 \%$ of the time)

Percentage of time faculty attends

to spirituality in the classroom

(0\% to $100 \%$ of the time)
53

80

12

7

1

76

62

8

5

2

49.7

40.5

5.2

3.3

1.3

34.6

52.3

7.8

4.6

.7

$3.31 \quad 1.26$

$2.70 \quad .96$

$2.77 \quad 1.12$
139

13

1

32.31

25.82

23.64

22.44 
Table 3.1

(Continued)

$\underline{N} \quad$ Percentage $\quad \underline{M} \quad \underline{\text { SD }}$

(\%)

Percentage of time faculty attends

to spirituality in supervision

(0\% to $100 \%$ of the time)

$19.61 \quad 21.30$

Religious organization

None

Jewish

Protestant

17

11.1

$\begin{array}{ll}6 & 3.9\end{array}$

Catholic

48

31.4

Latter-Day Saints (Mormon)

24

15.7

Buddhist

24

15.7

Hindu

$2 \quad 1.3$

Islamic/Muslim

3

2.0

Other

$2 \quad 1.3$

Seventh Day Adventist

Missing

$16 \quad 10.5$

$9 \quad 5.9$

$2 \quad 1.3$

Actively participates in

religious organization

$\begin{array}{lrr}\text { Yes } & 95 & 62.1 \\ \text { No } & 55 & 35.9 \\ \text { Other } & 1 & .7 \\ \text { Missing } & 2 & 1.3\end{array}$


Table 3.2

Sex of Supervisors \#1 and \#2

N Percentage

(\%)

Sex of supervisor \#1

Female

Male

Missing

9

5.9

$138 \quad 90.2$

6
3.9

Sex of supervisor \#2

Female

Male

Missing

$139 \quad 90.8$

$\begin{array}{ll}8 & 5.2\end{array}$

6
8.9




\section{CHAPTER IV}

\section{RESULTS}

In the Cubbyhole, Ruth returns to the past. The laptop becomes a sand tray. Ruth is six years old again, the same child, her broken arm healed, her other hand holding a chopstick, ready to divine the words. Bao Bomu comes, as always, and sits next to her. Her face is smooth, as beautiful as it is in the photo. ... And side by side, Ruth and her grandmother begin. Words flow. They have become the same person, six years old, sixteen, forty-six, eighty-two.

-Amy Tan, The Bonesetter's Daughter (pp. 402-403)

This chapter delineates the results of the analyses performed on the data to test the hypotheses. After describing the preliminary and primary analyses, the following sections will address each hypothesis and present the findings.

\section{Preliminary Analyses and Procedures}

Factor Analysis and Reliability Testing of the Spiritual Issues in Supervision Scale (SISS) with Primary Data

A preliminary analysis of the SISS using the primary data was necessary for this study because the researcher implemented a new instrument. Using a Principal Component Analysis (PCA), a factor analysis using a varimax rotation was performed on the SISS data. Eigenvalues greater than one served as the criterion for calculating the number of factors, accepting factor loadings equal to or higher than .33 . Table 4.1 illustrates the initial eigenvalues for the PCA, and Table 4.2 demonstrates the extraction sums and rotation sums of squared loadings for the PCA. The Kaiser-Meyer-Olkin measure of sampling adequacy was .943 , which indicated that the distribution of values was excellent for conducting factor analysis (George \& Mallery, 2001). Moreover, 
Bartlett's Test of Sphericity produced a significant value of $<.001$, which showed that the data were approximately multivariate normal, which was satisfactory for factor analysis (George \& Mallery, 2001).

The PCA produced four underlying factors for the SISS. Table 4.3 displays the rotated factor loadings for items in the measure. These results differed from the pilot study, which revealed seven factors with a much smaller sample. The four factors accounted for 69.9 percent of the sample variance. The first factor was by far the largest, with 14 items. The number of loaded items dropped significantly on the remaining three factors, with six items loading on factor two, five on factor three, and four on factor four. Factor one accounted for 24.11 percent of the sample variance, and 16.80 percent could be attributed to factor two. Factor three accounted for 15.11 percent, and 13.90 percent could be attributed to factor four.

A reliability analysis of the SISS data included 257 cases, given that several participants did not complete the entire instrument. This test produced a coefficient (Cronbach's alpha) of .975 for the entire scale. The researcher also conducted reliability analyses for each of the four factors, all of which produced acceptable internal consistency: (1) Factor one: .960; (2) Factor two: .896; (3) Factor three: .911; (4) Factor four: .881 . 


\section{Total Score for the SISS}

The total score for the SISS was calculated in order to test the hypotheses addressing the frequency of spiritual issues addressed in supervision. A lower sum score on the SISS meant that the therapist reported that spiritual issues were addressed less frequently than if there was a higher score. For the sample in this study, SISS scores ranged from 30 to 150 , with a mean of 78.68 , and a standard deviation of 28.17 .

\section{Total Score for the SSI Subscales}

According to Long et al. (1996), the SSI has three subscales: (1)

Affiliative/Authoritative; (2) Non-Directive/Directive; and (3) Self-Disclosing/Non-SelfDisclosing. Long et al. (1996) emphasized that "each subscale on the SSI is distinct, and the scores should not be totaled" (p. 605). The subscale totals were calculated after reverse scoring items six, eight, nine, $10,11,12$, and 19 . The creators stated that researchers ought to consider supervisory style not as dichotomous, but continuous. In the first scale, scores ranged from six to 24 . A more affiliative style was indicated with scores from 19 to 24 , and a more authoritative style was suggested with scores from six to 11. For the second scale (ranging from six to 24), scores of 19 to 24 illustrated a nondirective style, and scores from six to 11 indicated a directive supervisor. Lastly, a more self-disclosing supervisor would have scores from 22 to 28 , and a supervisor who tends to be non-self-disclosing would be rated with scores from seven to 13 . The scores on this scale ranged from seven to 28 (Long et al., 1996). 


\section{Recoded Items for Therapist-Supervisor Pairing}

For the majority of the sample, each therapist reported on two supervisors. The number of supervisors, therefore, easily eclipsed the number of therapists in the analyses. Hypotheses 1a, 1b, 2a, 2b, and 4 focused on supervisors and therapists separately, so the different numbers in each group did not pose a problem for the statistical analyses. In Hypotheses $3 \mathrm{a}$ and $3 \mathrm{~b}$, however, the interactions between therapist-supervisor pairs were examined. For 141 of these pairings, the therapist was coded twice. There were 12 participants who rated only one supervisor, so they were coded once. This adjustment helped create more equal groups for the factorial ANOVAs.

\section{Other Preliminary Analyses}

In order to determine if any confounding variables existed, analyses were conducted with the demographics and the main variables of the study—namely, the total SISS score, and the total scores for each of the SSI subscales. Pearson's correlations were run with 18 demographic variables and the total SISS score (see Table 4.4). The results indicated significant relationships with the epistemology of supervisor $(\underline{r}=.180, \underline{p}<.01)$, the number of male supervisors the participant had $(\underline{\mathrm{r}}=.154, \underline{\mathrm{p}}<.05)$, and the number of female supervisors she/he had $(\underline{r}=.186, \underline{p}<.01)$. There were also significant correlations between the total SISS score and the ratings of the percentage of time the therapist addressed spirituality in therapy $(\underline{\underline{r}}=.195, \mathrm{p}<.01)$, as well as the percentage of time the program faculty spent addressing spirituality in the classroom $(\underline{\mathrm{r}}=.396, \mathrm{p}<.01)$, and in supervision $(\underline{r}=.448, \underline{p}<.01)$. 
For the Affiliative/Authoritative subscale of the SSI, there was only one significant correlation with this variable and the epistemology rating of supervisor one ( $\underline{r}$ $=.164, \underline{\mathrm{p}}<.05)$. The Directive/Non-Directive variable indicated significant relationships with student status $(\underline{r}=.161, \underline{p}<.01)$ and the student's rating of her/his epistemology $(\underline{r}=$ $.135, \mathrm{p}<.05)$. After running correlations for the Self-Disclosing/Non-Self-Disclosing total subscale score, it was found that significant relationships existed with student status $(\underline{r}=.148, \underline{p}<.05)$ and whether or not the student was actively religious $(\underline{r}=.140, \underline{p}<$ $.05)$. There were also correlations with the percentage of time spirituality is addressed in the classroom $(\mathrm{r}=.135, \mathrm{p}<.05)$ and the percentage of time it is addressed in supervision $(\underline{\mathrm{r}}=.233, \mathrm{p}<.01)$. Although these confounding variables are important, they are not central to the hypotheses of this study. Given that they fall outside the scope of this research, the best way to address the correlations is to build the variables into future studies.

\section{Primary Analysis: Testing the Research Hypotheses}

Hypothesis 1a: There will be a relationship between the sex of the therapist and ratings of supervisory style

Three one-way ANOVAs were conducted to test this hypothesis. Therapist sex (two levels: male, female) served as the independent variable, and the three levels of the SSI functioned as the dependent variables (Affiliative/Authoritative; Directive/NonDirective; Self-Disclosing/Non-Self-Disclosing). The researcher ran ANOVA analyses for all three subscales. With the Affiliative/Authoritative subscale (see Table 4.5), no significant differences were found between ratings of male therapists and female 
therapists, $\underline{F}(1,104)=.454, \underline{p}=.502, \mathrm{Eta}^{2}=.004$. A total of 106 participants were included in this analysis, with 67 females and 39 males. Second, for the Directive/NonDirective subscale (see Table 4.6), there was no significance, $\underline{F}(1,112)=.072, \underline{p}=.788$, $\mathrm{Eta}^{2}=.001$. There were 114 therapists in this analysis: 73 females and 41 males. Lastly, when the analysis was run for the Self-Disclosing/Non-Self-Disclosing subscale (see Table 4.7), no significance was produced between groups, $\underline{\mathrm{F}}(1,133)=.807, \mathrm{p}=.371$, $\operatorname{Eta}^{2}=.006$. One hundred thirty-five therapists were in this analysis, with 87 females and 48 males. Hypothesis 1a, therefore, was not supported for all three subscales of the SSI (see Table 4.8 for means and standard deviations).

Hypothesis $1 \mathrm{~b}$ : There will be a relationship between the sex of the therapist and frequency of spiritual issues addressed in supervision

A one-way ANOVA was produced to test this hypothesis, with therapist sex (two levels: male, female) as the independent variable, and the total SISS score as the dependent variable (see Table 4.9). One hundred twenty-one participants were included in this analysis. Seventy-eight of them were female, and 43 were male. No significance was found, $\underline{\mathrm{F}}(1,119)=2.935, \mathrm{p}=.089, \mathrm{Eta}^{2}=.024$; therefore, hypothesis $1 \mathrm{~b}$ was not supported (see Table 4.10 for means and standard deviations).

Hypothesis 2a: There will be a relationship between the sex of the supervisor and ratings of supervisory style

Three one-way ANOVAs were conducted to address this hypothesis. The sex of the supervisor (two levels: female, male) was the independent variable, and the three levels of supervisory style (Affiliative/Authoritative; Directive/Non-Directive; Self- 
Disclosing/Non-Self-Disclosing) were the dependent variables. In the first analysis, there were 111 females and 119 males to produce a total of 230 supervisors rated. With the Affiliative/Authoritative subscale (see Table 4.11), significance was found, $\underline{F}(1,228)=$ $5.086, \mathrm{p}=.025, \mathrm{Eta}^{2}=.022$. Male supervisors were rated as more affiliative $(\mathrm{M}=20.82)$ than female supervisors $(M=19.94)$, although both sexes were scored in the range of a more affiliative style (19 through 24) (Long et al., 1996). The second analysis with the Directive/Non-Directive subscale (see Table 4.12) included the ratings of 117 female supervisors and 123 male supervisors, which created a total of 240 . No significance was found, $\underline{F}(1,238)=.500, \underline{p}=.480, \operatorname{Eta}^{2}=.002$. In the third analysis with the SelfDisclosing/Non-Self-Disclosing subscale (see Table 4.13), there were 286 supervisors total, with 144 females rated and 142 males rated. When results were produced, there was no significance, $\underline{F}(1,284)=.060, \underline{p}=.807, E^{2} a^{2}=.000$. Overall, there were significant group differences between the female supervisors and male supervisors only in relation to the Affiliative/Authoritative level, which indicated that the results supported hypothesis 2a for one subscale of the SSI, but not for the other two subscales (see Table 4.14 for means and standard deviations).

Hypothesis $2 b$ : There will be a relationship between the sex of the supervisor and the frequency of spiritual issues addressed in supervision

A one-way ANOVA generated results for this hypothesis. Of the 257 rated supervisors included in this analysis, 127 were female and 130 were male. There was no significance produced, $\mathrm{E}(1,255)=.118, \mathrm{p}=.731, \mathrm{Eta}^{2}=.000($ see Table 4.15$)$. 
Hypothesis $2 \mathrm{~b}$, therefore, was not supported (see Table 4.16 for means and standard deviations).

Hypothesis 3a: There will be an interaction effect between the sex of the therapist and sex of the supervisor on ratings of supervisory style

Three 2 (therapist sex) X 2 (supervisor sex) factorial ANOVAs were used to test this hypothesis. The independent variables were therapist sex (two levels: female, male) and supervisor sex (two levels: female, male). The dependent variables were the three levels of supervisory style (Affiliative/Authoritative; Directive/Non-Directive; SelfDisclosing/Non-Self-Disclosing). The analysis was conducted three times—once for each subscale. The four groups in the factorial ANOVA were (1) female therapist reporting on female supervisor, (2) female therapist reporting on male supervisor, (3) male therapist reporting on male supervisor, and (4) male therapist reporting on female supervisor. As previously mentioned, 141 therapists rated two supervisors; therefore, to calculate accurately the therapist/supervisor pairings, these therapists were coded twice—once for each supervisor rated. Given this adjustment, 147 female therapists and 83 male therapists, and 111 female rated supervisors and 119 male rated supervisors were included in the first analysis with the Affiliative/Authoritative subscale. The number of female therapist/female supervisor pairings was 70 , and the number of female therapist/male supervisor ratings was 77 . There were 41 male therapist/female supervisor pairs, and 42 male therapist/male supervisor pairs. In the results (see Table 4.17), there was no significant therapist sex by supervisor sex interaction, $\underline{\mathrm{F}}(1,226)=.044, \underline{\mathrm{p}}=.834$, $E_{t^{2}}=.000$. Given that there was no interaction effect, the main effects could be 
interpreted. There was no significant main effect for therapist sex: Female therapists ( $M=$ 20.31) did not rate their supervisors significantly differently from male therapists ( $M=$ 20.50), $\underline{\mathrm{F}}(1,226)=.206, \mathrm{p}=.651, \mathrm{Eta}^{2}=.004$. There was a significant main effect for supervisor sex. Findings indicate that male supervisors $(M=20.86)$ were rated higher, or more affiliative, than female supervisors $(\mathrm{M}=19.95), \underline{\mathrm{F}}(1,226)=4.946, \mathrm{p}=.027, \mathrm{Eta}^{2}=$ .021 .

With the analysis of the Non-Directive/Directive level of the SSI (see Table 4.18), the responses of 155 female therapists and 85 male therapists were included in the analysis. In addition, there were 117 female supervisors and 123 male supervisors that were rated. The female therapist/female supervisor pairs equaled 75 , and the female therapist/male supervisor equaled 80 . There were 42 male therapist/female supervisor pairs, and 43 male therapist/male supervisor pairs. There was no significant main effect for therapist sex, $\underline{\mathrm{F}}(1,236)=.020, \mathrm{p}=.889, \mathrm{Eta}^{2}=.000$. Female therapists $(\mathrm{M}=21.30)$ produced similar scores as male therapists $(M=21.35)$. There was no significant main effect for supervisor sex, $\mathrm{F}(1,236)=.568, \mathrm{p}=.452, \mathrm{Eta}^{2}=.002$. Results show that female supervisors $(M=21.19)$ had similar ratings as male supervisors $(M=21.46)$. There was no therapist sex by supervisor sex interaction, $\underline{F}(1,236)=.073, \underline{p}=.788$, Eta ${ }^{2}$ $=.000$. The means for all four groups were similar: (1) female therapist/female supervisor ( $M=21.21)$; (2) female therapist/male supervisor $(M=21.39)$; (3) male therapist/female supervisor $(M=21.17)$; (4) male therapist/male supervisor $(M=21.54)$. In general, both female and male therapists rated their supervisors as behaving in a non-directive manner, as in the SSI scores of 19-27 reflect more non-directive styles. 
The factorial ANOVA results for the Self-Disclosing/Non-Self-Disclosing scale (see Table 4.19) showed no significant main effect for therapist sex. Female therapists (M $=21.47)$ produced similar scores as male therapists $(\mathrm{M}=20.77), \underline{\mathrm{F}}(1,282)=1.42, \mathrm{p}=$ $.234, \mathrm{Eta}^{2}=.005$. Likewise, there was no significant main effect for supervisor sex. Male supervisors ( $M=21.24)$ were rated with scores comparable to female supervisors ( $M=$ 20.99), $\underline{\mathrm{F}}(1,282)=.184, \underline{\mathrm{p}}=.668, \mathrm{Eta}^{2}=.001$. There was no significant therapist sex by supervisor sex interaction, $\underline{\mathrm{F}}(1,282)=.634, \underline{\mathrm{p}}=427, \mathrm{Eta}^{2}=.002$. The analysis produced the following means: (1) female therapist/female supervisor $(M=21.57)$; (2) female therapist/male supervisor $(M=21.36)$; (3) male therapist/female supervisor $(M=20.42)$; (4) male therapist/male supervisor $(M=21.13)$. For this factorial ANOVA, there were 186 female therapists and 100 male therapists included. Ratings of 144 female supervisors and 142 male supervisors were also incorporated in the analysis. There were 91 female therapist/female supervisor pairs, 95 female therapist/male supervisor pairs, 53 male therapist/female supervisor pairs, and 47 male therapist/male supervisor pairs.

Overall, hypothesis 3 a was not supported, as no interaction effects occurred between therapist sex and supervisor sex on the three levels of supervisory style. It is important to point out, however, that a significant main effect emerged with supervisor sex with the Affiliative/Authoritative level. Both female and male supervisors fell into the affiliative range of this subscale (19 to 24); however, a significant group difference became apparent as male supervisors were rated as more affiliative than female supervisors. Please refer to Table 4.20 for means and standard deviations. 
Hypothesis $3 \mathrm{~b}$ : There will be an interaction effect between sex of the therapist and sex of the supervisor on the frequency of spiritual issues addressed in supervision

A 2 (therapist sex) X 2 (supervisor sex) factorial ANOVA was generated to attend to this hypothesis (See Table 4.21). The independent variables were therapist sex and supervisor sex (two levels: female, male). The dependent variable was the frequency of spiritual issues addressed in supervision, represented in the total SISS score. Four groups were tested: (1) female therapist reporting on female supervisor, (2) female therapist reporting on male supervisor, (3) male therapist reporting on male supervisor, and (4) male therapist reporting on female supervisor. In this analysis, 165 female therapists and 92 male therapists were included, as well as ratings of 127 female supervisors and 130 male supervisors. There were 80 female therapist/female supervisor pairs and 85 female therapist/male supervisor pairs. In addition, there were 47 male therapist/female supervisor pairs and 45 male therapist/male supervisor pairs.

A significant therapist sex by supervisor sex interaction emerged in this analysis, $\underline{F}(1,253)=4.143, \underline{p}=.043, \operatorname{Eta}^{2}=.016$. Scores of female therapist/female supervisor pairs $(M=83.76)$ were higher than female therapist/male supervisor pairs $(M=79.51)$. Also, scores of male therapist/male supervisor pairs $(M=79.07)$ were higher than male therapist/female supervisor pairs $(M=68.60)$. Findings indicate, therefore, that female therapists rated female supervisors as addressing spirituality more frequently than male supervisors. Results also suggest that male therapists rated male supervisors as addressing spirituality more frequently than female supervisors. It was evident, then, that these findings supported hypothesis $3 \mathrm{~b}$. There was a significant main effect for therapist sex, $\underline{F}$ 
$(1,253)=4.652, \underline{p}=.032, \mathrm{Eta}^{2}=.018 ;$ however, due to the presence of a significant interaction, the main effect was not interpreted. There was no significant main effect for supervisor sex, $\underline{\mathrm{F}}(1,253)=.740, \mathrm{p}=.391, \mathrm{Eta}^{2}=.003$ (see Table 4.22 for means and standard deviations).

Hypothesis 4: A relationship will emerge between supervisory style and the frequency of spiritual issues addressed in supervision

A Pearson's correlation analysis (pairwise) was conducted between the total score of the SISS and the three subscales of the SSI (Affiliative/Authoritative, Directive/NonDirective; Self-Disclosing/Non-Self-Disclosing). Table 4.23 presents the results of this analysis. With the Affiliative/Authoritative scale and the total SISS score, correlation ( $r=$ .329) was significant at the .01 level (2-tailed). The positive correlation indicated that based on the student's perspective, the more affiliative the supervisor, the higher the frequency with which the supervisor addressed spiritual issues in supervision. If the participant perceived the supervisor as more authoritative, she/he rated the supervisor as talking about spiritual issues less frequently. A significant correlation $(\underline{r}=.466)$ at the .01 level (2-tailed) also emerged with the analysis between the Self-Disclosing/Non-SelfDisclosing subscale and the total SISS score. Again, given that the correlation was positive, these results suggest that according to therapists-in-training, a relationship exists between ratings on the Self-Disclosing/Non-Self-Disclosing subscale and the frequency with which the supervisor addresses spiritual issues in supervision. If participants tended to view their supervisors as more non-self-disclosing, they rated them as looking at spiritual issues less frequently. No significant correlation was generated when analyzing 
correlations between the total SISS score and the Directive/Non-Directive subscale. The hypothesis was supported, therefore, for the Affiliative/Authoritative and Disclosing/Non-Self-Disclosing subscales, but not for the Directive/Non-Directive subscale. 


\section{Table 4.1}

Total Variance Explained-Initial Eigenvalues for the Principal Component Analysis of the Spiritual Issues in Supervision Scale (SISS)

Component

1

2

3

4

5

6

7

8

9

10

11

12

13

14

15

16

17

18

19

20

21

22

23
Eigenvalue

16.94

1.55

1.41

1.08

.88

.75

.73

.68

.63

.54

.47

.42

.40

.37

.34

.29

.28

.26

.25

.23

.22

.22

.20
$\%$ of Variance

56.48

5.16

4.68

3.60

2.94

2.51

2.44

2.26

2.08

1.79

1.58

1.38

1.32

1.23

1.12

.98

.93

.86

.84

.77

.73

.68

.67
Cumulative $\%$

56.48

61.63

66.32

69.92

72.86

75.37

77.81

80.07

82.16

83.94

85.52

86.91

88.22

89.46

90.58

91.56

92.49

93.35

94.19

94.97

95.69

96.38

97.05 
Table 4.1

(Continued)

Component

24

25

26

27

28

29

30
Eigenvalue

$\%$ of Variance

.58

.56

.49

.44

.38

.32

.18
Cumulative \%

97.63

98.19

98.68

99.13

99.50

99.82

100.00 
Table 4.2

Total Variance Explained-Extraction Sums and Rotation Sums of Squared Loadings for the Principal Component Analysis of the Spiritual Issues in Supervision Scale (SISS)

\begin{tabular}{|c|c|c|c|c|c|c|}
\hline \multirow[b]{2}{*}{ Component } & \multicolumn{3}{|c|}{ Extraction Sums of Sq. Loadings } & \multicolumn{3}{|c|}{ Rotation Sums of Sq. Loadings } \\
\hline & Total & $\%$ Variance & Cum \% & Total & $\%$ Variance & Cum \% \\
\hline 1 & 16.94 & 56.48 & 56.48 & 7.23 & 24.11 & 24.11 \\
\hline 2 & 1.58 & 5.16 & 61.63 & 5.04 & 16.80 & 40.91 \\
\hline 3 & 1.41 & 4.68 & 66.32 & 4.53 & 15.11 & 56.02 \\
\hline 4 & 1.08 & 3.60 & 69.92 & 4.17 & 13.90 & 69.92 \\
\hline
\end{tabular}


Table 4.3

Rotated Factor Loadings for Items in the Spiritual Issues in Supervision Scale (SISS)

\begin{tabular}{|c|c|c|c|c|}
\hline Item & Factor 1 & Factor 2 & Factor 3 & Factor 4 \\
\hline Divorce & .72 & & & \\
\hline Trauma & .70 & & .34 & \\
\hline Gender & .66 & .45 & & \\
\hline Suicide & .65 & & & .35 \\
\hline Sexual Orientation & .63 & & & .40 \\
\hline Sex & .62 & .43 & & \\
\hline Abortion & .62 & & & .57 \\
\hline Substance Abuse & .61 & & .42 & \\
\hline Marriage & .59 & & & \\
\hline Ethical Issues & .58 & .45 & & \\
\hline Power & .54 & .51 & .34 & \\
\hline Fertility & .54 & & .30 & .54 \\
\hline Children & .54 & .39 & .47 & \\
\hline Parenting & .53 & .37 & .45 & \\
\hline Client Support System & .50 & .36 & & .46 \\
\hline Supervisory Relationship & & .83 & & \\
\hline Therapist Support System & & .67 & & .37 \\
\hline Self-of-Therapist & & .66 & & .34 \\
\hline Case Conceptualization & & .59 & .38 & \\
\hline Self-Esteem & .55 & .56 & & \\
\hline Identity & .44 & .51 & & .41 \\
\hline Ethnicity & & & .83 & \\
\hline Race & & & .78 & \\
\hline Culture & & & .77 & .35 \\
\hline
\end{tabular}


Table 4.3

(Continued)

$\begin{array}{lllll}\text { Item } & \text { Factor } 1 & \text { Factor } 2 & \text { Factor } 3 & \text { Factor } 4\end{array}$

Assessment

Treatment Plan

.45

.49

.52

Religion

.48

.79

Hope

.40

.59

Grief

.40

.35

.52

Note. Loadings of .33 or higher were considered. 


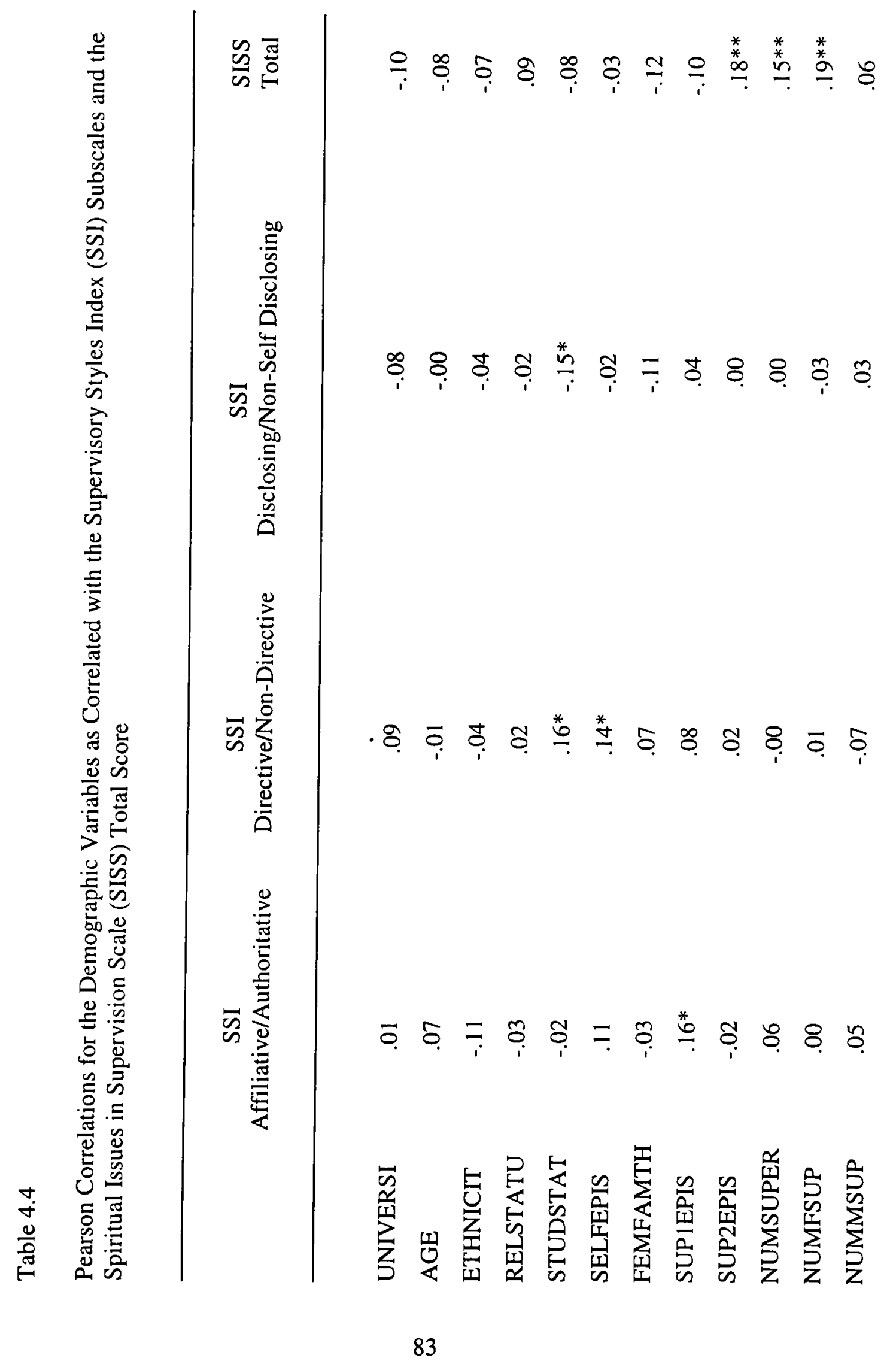




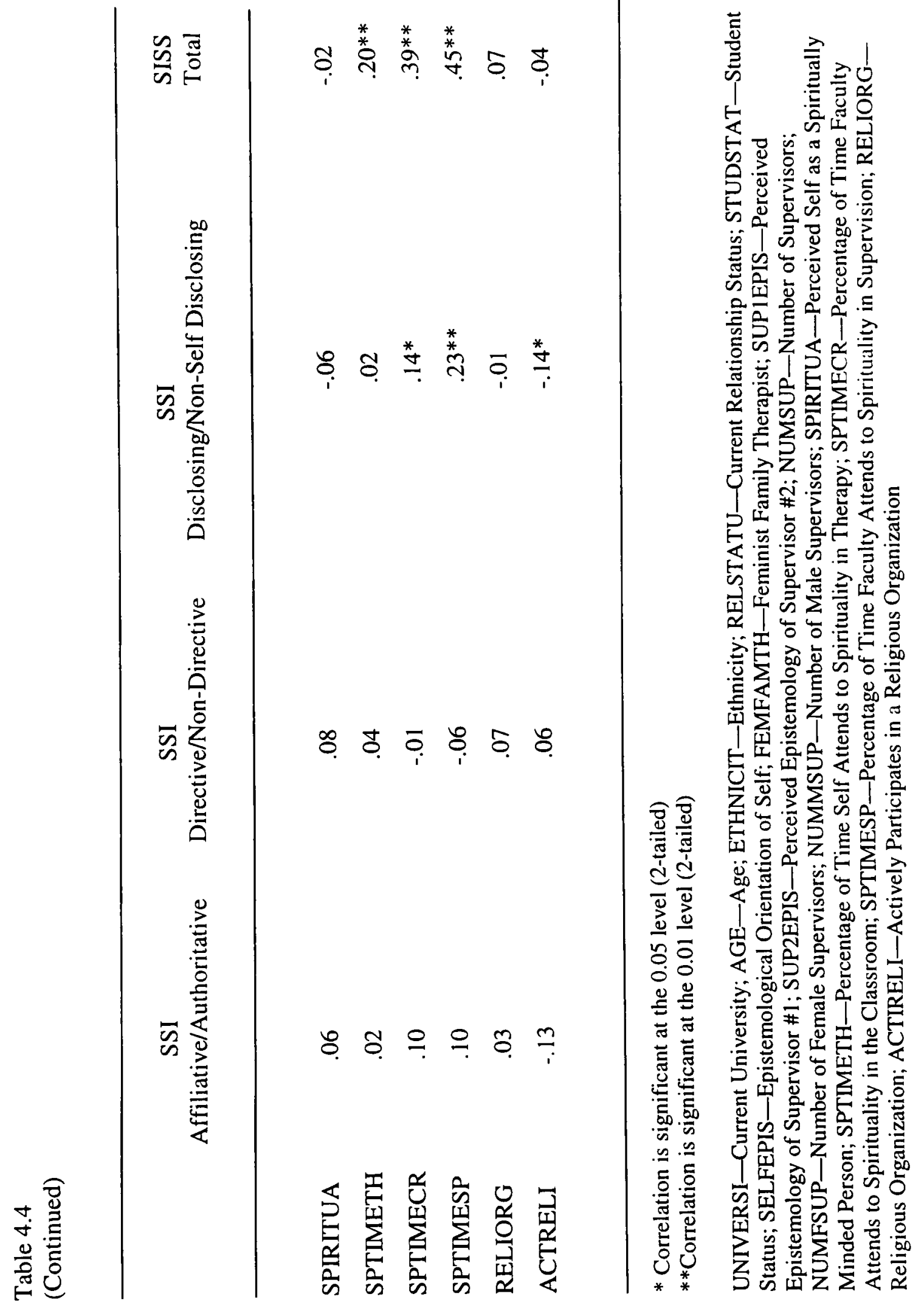


Table 4.5

Univariate Analysis of Variance for Scores on the Affiliative/Authoritative Subscale of the Supervisory Styles Index (SSI)

Source

SS

df

MS

F

$\operatorname{Eta}^{2}$

Sex of Therapist

11.07

1

11.07

$.45^{*}$

.00

Error

2537.81

104

24.40

${ }^{*} \underline{p}=.50$, n.s. 
Table 4.6

Univariate Analysis of Variance for Scores on the Directive/Non-Directive Subscale of the Supervisory Styles Index (SSI)

Source

SS

$\mathrm{df}$

MS

F

$\mathrm{Eta}^{2}$

Sex of Therapist

1.63

1

1.63

$.07 *$

.00

Error

2519.81

112

22.50

${ }^{*} \mathrm{p}=.79$, n.s. 
Table 4.7

Univariate Analysis of Variance for Scores on the Self-Disclosing/Non-Self-Disclosing Subscale of the Supervisory Styles Index (SSI)

\begin{tabular}{lrrrrr}
\hline Source & SS & df & MS & $\underline{F}$ & Eta $^{2}$ \\
\hline Sex of Therapist & 43.36 & 1 & 43.36 & $.81^{*}$ & .00 \\
Error & 7141.72 & 133 & 53.70 & & \\
\hline
\end{tabular}

${ }^{*} \mathrm{p}=.37$, n.s. 
Table 4.8

Means and Standard Deviations for Ratings of Supervisory Style by Sex of Therapist

Therapist

Supervisory Style

Female

Male

Affiliative/Authoritative $(\mathrm{N}=106)$

$\mathrm{M}$

SD

40.62

41.28

5.12

4.61

Directive/Non-Directive $(\mathrm{N}=114)$

$\mathrm{M}$

42.51

42.76

$\mathrm{SD}$

4.88

4.48

Self-Disclosing/Non-Self-Disclosing $(\mathrm{N}=135)$

M

42.85

41.67

SD

7.30 
Table 4.9

Univariate Analysis of Variance for Scores on the Spiritual Issues in Supervision Scale (SISS)

Source

SS

df

MS

$\underline{F}$

$\mathrm{Eta}^{2}$

\begin{tabular}{lrrrrr}
\hline Sex of Therapist & 7243.07 & 1 & 7243.07 & $2.9^{*}$ & .02 \\
Error & 293668.35 & 119 & 2467.80 & \\
\end{tabular}

${ }^{*} \mathrm{p}=.09$, n.s. 
Table 4.10

Means and Standard Deviations for Frequency of Spiritual Issues Addressed in Supervision by Sex of Therapist

Frequency of Spiritual Issues

Addressed in Supervision $(\mathrm{N}=121)$
Therapist

Female

Male 
Table 4.11

Univariate Analysis of Variance for Scores on the Affiliative/Authoritative Subscale of the Supervisory Styles Index (SSI)

Source

SS

df

MS

$\underline{F}$

$\operatorname{Eta}^{2}$

Sex of Supervisor

45.14

1

45.14

$5.09 *$

.02

Error

2023.85

228

$* \underline{p}<.05$ 
Table 4.12

Univariate Analysis of Variance for Scores on the Directive/Non-Directive Subscale of the Supervisory Styles Index (SSI)

Source

SS

df

MS

$\underline{F}$

Eta $^{2}$

Sex of Supervisor

3.53

1

3.53

$.50^{*}$

.00

Error

1676.77

238

7.05

${ }^{*} \mathrm{p}=.48$, n.s. 
Table 4.13

Univariate Analysis of Variance for Scores on the Self-Disclosing/Non-Self-Disclosing Subscale of the Supervisory Styles Index (SSI)

Source

SS

df

MS

$\underline{F}$

$\mathrm{Eta}^{2}$

Sex of Supervisor

1.32

1

.06

.00

Error

6236.67

284

21.96

${ }^{*} \mathrm{p}=.81$, n.s. 
Table 4.14

Means and Standard Deviations for Ratings of Supervisory Style by Sex of Supervisor

Supervisor

Supervisory Style

Female

Male

Affiliative/Authoritative $(\mathrm{N}=230)$

$M$

19.94

20.82

SD

3.50

2.40

Directive/Non-Directive $(\mathrm{N}=240)$

$\mathrm{M}$

21.20

21.44

SD

2.84

2.46

Self-Disclosing/Non-Self-Disclosing ( $\mathrm{N}=286)$

$\mathrm{M}$

21.15

21.28

$\mathrm{SD}$

4.25

5.08 
Table 4.15

Univariate Analysis of Variance for Scores on the Spiritual Issues in Supervision Scale (SISS)

\begin{tabular}{lrrrrr}
\hline Source & \multicolumn{1}{l}{ SS } & df & MS & $\underline{\text { F }}$ & Eta $^{2}$ \\
\hline Sex of Supervisor & 93.77 & 1 & 93.77 & .12 & .00 \\
Error & 202126.78 & 255 & 792.65 & & \\
\hline
\end{tabular}

${ }^{*} \mathrm{p}=.73$, n.s. 
Table 4.16

Means and Standard Deviations for Frequency of Spiritual Issues Addressed in Supervision by Sex of Supervisor

Frequency of Spiritual Issues

Addressed in Supervision ( $\mathrm{N}=257)$
Supervisor

Female Male
$\mathrm{M}$

$\mathrm{SD}$
78.15

29.27
79.35

27.02 
Table 4.17

Univariate Analysis of Variance for Scores on the Affiliative/Authoritative Subscale of the Supervisory Styles Index (SSI)

\begin{tabular}{|c|c|c|c|c|c|}
\hline Source & SS & $\mathrm{df}$ & MS & $\underline{F}$ & $\mathrm{Eta}^{2}$ \\
\hline Sex of Therapist & 1.84 & 1 & 1.84 & .21 & .00 \\
\hline Sex of Supervisor & 44.24 & 1 & 44.24 & $4.95^{*}$ & .02 \\
\hline $\begin{array}{l}\text { Sex of Therapist X } \\
\text { Sex of Supervisor }\end{array}$ & .40 & 1 & .40 & .04 & .00 \\
\hline Error & 2021.57 & 226 & 8.95 & & \\
\hline
\end{tabular}

$* \mathrm{p}<.05$ 
Table 4.18

Univariate Analysis of Variance for Scores on the Directive/Non-Directive Subscale of the Supervisory Styles Index (SSI)

\begin{tabular}{lrrrrr}
\hline Source & SS & $\mathrm{df}$ & MS & $\underline{F}$ & Eta $^{2}$ \\
\hline & & & & & \\
Sex of Therapist & .14 & 1 & .14 & .02 & .00 \\
Sex of Supervisor & 4.04 & 1 & 4.04 & .57 & .00 \\
Sex of Therapist X & .52 & 1 & .52 & .07 & .00 \\
Sex of Supervisor & 1676.11 & 236 & 7.10 & & \\
Error & & & & & \\
\hline
\end{tabular}


Table 4.19

Univariate Analysis of Variance for Scores on the Self-Disclosing/Non-Self-Disclosing Subscale of the Supervisory Styles Index (SSI)

\begin{tabular}{lrrrrr}
\hline Source & \multicolumn{1}{l}{ SS } & $\mathrm{df}$ & $\mathrm{MS}$ & $\underline{F}$ & $\mathrm{Eta}^{2}$ \\
\hline & & & & & \\
Sex of Therapist & 31.18 & 1 & 31.18 & 1.42 & .01 \\
Sex of Supervisor & 4.04 & 1 & 4.04 & .18 & .00 \\
$\begin{array}{l}\text { Sex of Therapist X } \\
\text { Sex of Supervisor }\end{array}$ & 13.91 & 1 & 13.91 & .63 & .00 \\
Error & 6190.22 & 282 & 21.95 & & \\
\hline
\end{tabular}


Table 4.20

Means and Standard Deviations for Ratings of Supervisory Style by Sex of Supervisor and Sex of Therapist

\begin{tabular}{|c|c|c|c|c|c|c|}
\hline & \multicolumn{2}{|c|}{$\begin{array}{l}\text { Affiliative/ } \\
\text { Authoritative } \\
(\mathrm{N}=230)\end{array}$} & \multicolumn{2}{|c|}{$\begin{array}{l}\text { Directive/ } \\
\text { Non-Directive } \\
(\mathrm{N}=240)\end{array}$} & \multicolumn{2}{|c|}{$\begin{array}{l}\text { Self-Disclosing/ } \\
\text { Non-Self- } \\
\text { Disclosing } \\
(\mathrm{N}=286)\end{array}$} \\
\hline & $\mathbf{M}$ & SD & $\mathrm{M}$ & $\mathrm{SD}$ & M & $\mathrm{SD}$ \\
\hline \multicolumn{7}{|l|}{ Therapist X Supervisor } \\
\hline Female X Female & 19.90 & 3.41 & 21.21 & 2.84 & 21.57 & 5.20 \\
\hline Female X Male & 20.73 & 2.62 & 21.39 & 2.53 & 21.36 & 4.24 \\
\hline Male X Female & 20.00 & 3.68 & 21.17 & 2.88 & 20.42 & 4.81 \\
\hline Male X Male & 21.00 & 1.93 & 21.53 & 2.35 & 21.13 & 4.33 \\
\hline
\end{tabular}


Table 4.21

Univariate Analysis of Variance for Scores on the Spiritual Issues in Supervision Scale (SISS)

\begin{tabular}{|c|c|c|c|c|c|}
\hline Source & SS & $\mathrm{df}$ & MS & $\underline{F}$ & $\mathrm{Eta}^{2}$ \\
\hline Sex of Therapist & 3591.18 & 1 & 3591.18 & $4.65^{*}$ & .02 \\
\hline Sex of Supervisor & 571.03 & 1 & 571.03 & .74 & .00 \\
\hline $\begin{array}{l}\text { Sex of Therapist X } \\
\text { Sex of Supervisor }\end{array}$ & 3198.13 & 1 & 3198.13 & $4.14^{*}$ & .02 \\
\hline Error & 195316.36 & 253 & 772.00 & & \\
\hline
\end{tabular}

${ }^{*} \underline{p}<.05$ 
Table 4.22

Means and Standard Deviations for Frequency of Spiritual Issues Addressed in Supervision by Sex of Supervisor and Sex of Therapist

Frequency of Spiritual Issues Addressed in Supervision

M SD

Therapist X Supervisor

Female X Female

83.76

29.02

Female X Male

79.51

27.50

Male X Female

68.60

27.44

Male X Male

79.07

26.39 


\section{Table 4.23}

Pearson's Correlations for the Supervisory Styles Index (SSI) Subscales and the Spiritual Issues in Supervision (SISS) Total Score

SISS

Subscales
SISS

Total Score

Affiliative/Authoritative

$.33 * *$

Directive/Non-Directive

$.47 *$

Self-Disclosing/Non-Self-Disclosing

$-.07$

**Correlation is significant at the 0.01 level (2-tailed) 


\section{CHAPTER V}

\section{DISCUSSION}

How wicked it would be, if we could, to call the dead back! She said not to me but to the chaplain, 'I am at peace with God.' She smiled, but not at me. Poi si tornò all' eterna fontana.

-C. S. Lewis, A Grief Observed, p. 64.

The findings of this study open the door for more exploration in the areas of spirituality, gender, and supervisory style in supervision. Several significant relationships emerged among these variables. This chapter will interpret the results of this study, as well as delineate implications of these findings.

\section{Overview of Main Research Question}

As discussed in Chapter I, the role of therapists is helping people who feel pain and sickness of the soul in their lives and relationships (Keating, 1994). Given that human beings suffer in life (Borysenko, 1999; Keating, 1994), it is essential for clinicians to address both the humanity and spirituality of clients (James, 1902/1997). Spirituality has appeared more frequently in the literature as it is becoming an accepted topic in the MFT field (Carlson \& Erickson, 2002; Coffey, 2002; Griffith \& Griffith, 2002; Senter \& Caldwell, 2002; Trepper, 2002; Walsh, 1999; Wendel, 2003). Senter and Caldwell (2002) stated, "Family therapists and other members of the mental health field are increasingly aware that spirituality is a powerful aspect of human experience" (p. 543). The acknowledgement that clinicians ought to address spirituality with clients (Griffith \& 
Griffith, 2002), therefore, has naturally extended to the need for supervisors to discuss this issue with therapists-in-training. Recent authors have argued that spirituality is a key construct for MFT supervisors and supervisees to consider (Carlson \& Erickson, 2001; Coffey, 2002; Miller, 1999; Prest et al., 1999; Stander et al., 1994). This study, in essence, has examined spirituality as a construct in supervision, based on the supervisee's perspective.

Supervision is a complex process; therefore, it would seem that several factors shape how therapists-in-training perceive the conversations about spirituality in this context. Other literature discussed that the sex of therapist and sex of supervisor influences the experiences of supervisees, given that gender issues relate to power and hierarchy (Ault-Riché, 1998; Long et al., 1996; McHale \& Carr, 1998; Moorehouse \& Carr, 2002). Moreover, supervisory style has emerged as a key factor affecting therapist/supervisor interactions (Anderson et al., 2000; Long et al., 1996). This study, therefore, explored these issues using the following guiding question: Is gender associated with variations in perceptions of supervisory style and the frequency with which spiritual issues are addressed in supervision?

\section{General Conclusions}

Clearly, spirituality in supervision is a new focus of study on the horizon in the MFT field. Likewise, integrating gender and supervisory style with spirituality in supervision is an area not yet explored. At the same time, each of these issues has emerged as an important facet in exploring MFT training. The following sections 
delineate the dimensions of this study by giving meaning and context to the relationships-or lack of relationships-among the variables, as evidenced by statistical analysis.

Development and Testing of the Spiritual Issues in Supervision Scale (SISS)

The development of the SISS occurred in two phases. First, a pilot study was conducted in order to test the measure and provide evidence for reliability and validity. Second, the SISS was included in the primary analysis of this study, which included a much larger and more adequate sample for testing psychometric properties and establishing factors. Through the second process, it was determined that the final structure of the entire instrument includes four subscales.

An examination of the 15 items loading on the first factor suggests that it has to do with the "Client System." The majority of the items describe presenting problems clients would bring to therapy-problems related to the client's family-of-origin and social support system. Examples of these items are divorce, trauma, suicide, sexual intimacy, substance abuse, and issues concerning children and parenting. The six items loading on the second factor seem to relate to the "Supervisory System." These items focus on areas of discussion a supervisee and supervisor would address in supervision, such as how a therapist would conceptualize the case, as well as his/her theory of therapy. The third factor, which consists of six items, appears to be associated with a "Diversity Lens." These items are issues clients do not typically present as problems in therapy but emerge as areas therapists need to consider and address throughout the therapeutic 
process, such as ethnicity, race, and culture. The items of assessment and treatment that also loaded highest on this third factor are likewise lenses through which clinicians consider a case. The fourth factor, comprised of four items, cluster around the theme of a "Lens of Meaning and Values." These items (religion, hope, grief, and morality) include areas that may help clients transcend and work through difficult situations, as well as give meaning to their circumstances.

Although an analysis of the measure produced loadings on all four factors, Factor 1 accounted for 56.48 percent of the variance, whereas the other three factors each represented less than 10 percent. This finding suggests that this scale is a uni-dimensional measure that taps into different aspects of supervision in which spirituality may be perceived as part of the conversation, whether overtly addressed or merely intuited. In addition, there were more multiple loadings on the primary factor analysis than with the pilot analysis. Perhaps with a larger and more diverse sample, the multifaceted and complex nature of supervision is more apparent than it was with the smaller, more homogeneous pilot sample. At the same time, the strong reliability of the measure suggests cohesiveness and consistency (Patten, 2000)—essential characteristics for a scale that one might want to use for research purposes.

Spirituality as a Construct. Recently, authors have addressed the difficulties in defining and researching spirituality. Wendel (2003) asserted that the definition of spirituality continues to expand in clinical literature, which can create ambiguity and negatively affect research methodologies. On the other hand, Miller and Thoresen (2003) emphasized that researchers can study spirituality, pointing out that historically, "science 
has studied phenomena that were or are not directly observable but that could be inferred indirectly through predicted effects" (p. 25). Indeed, spirituality is complex and therefore difficult to measure as a specifically definable construct (Wendel, 2003). As previously mentioned, the author developed a specific definition of spirituality that appeared on the SISS. Even though the author included this definition on the measure as a reference for respondents, it does not guarantee that they interpreted spirituality differently, given their varied experiences and viewpoints. Overall, it is challenging to find words that apply universally to naming all factors generated by the analysis of the SISS. The factor names that the researcher chose therefore, can be seen only as generalizations, not definable constructs.

Although there may not be consensus in the MFT field that spirituality needs to be integrated in treatment and training, there has certainly been support suggesting that it is a viable and important construct to consider. At the same time, the finding that the SISS and its subscales produced solid reliability suggests that the inclusion of spirituality in the supervisory context, while subjectively perceived, nevertheless can be measured.

The finding that spirituality is perceived to be a part of various aspects of supervision is consistent with recent literature regarding how and where spirituality manifests. Several authors discussed how spirituality is relational, recognizing that it emerges through discussions among people (Bava et al., 2002; Carlson \& Erickson, 2002; Carlson et al., 2002). Carlson et al. (2002) explained that "all spiritualities center in relational experiences with the divine, and/or with humanity, and/or with all of creation" (p. 216). It seems, therefore, that the results of the factor analysis of the SISS support the 
relevancy of exploring spirituality through the lens of supervision. Furthermore, the findings indicate that the SISS is a viable scale that could help future researchers explore this important emerging area.

\section{Spirituality and Supervisory Style}

Based on the literature, it was hypothesized that supervisory style was an important factor to consider when looking at spirituality in supervision. Findings suggested that a significant relationship exists among two of the ratings of supervisory style and the frequency with which spiritual issues are addressed in supervision. The Affiliative/Authoritative subscale and the Self-Disclosing/Non-Self-Disclosing subscale were significantly correlated with the total score on the SISS, and the correlations were positive. The Directive/Non-Directive subscale indicated no correlation. The correlation on the Affiliative/Authoritative subscale suggests that supervisors who were perceived by trainees to be more affiliative were also appeared to address spiritual issues more frequently in supervision. The correlation on the Self-Disclosing/Non-Self-Disclosing indicates that when therapists viewed supervisors as more self-disclosing, they also reported that spiritual issues were discussed more frequently in supervision. These results are consistent with the literature, which suggested that an open, respectful environment in supervision may facilitate communication about difficult topics, such as spirituality (Anderson et al., 2000; Ratliff et al., 2000). It makes sense that if a therapist perceives her/his supervisor as affiliative, she/he would feel more at-ease discussing spirituality. Perhaps an affiliative style would help a trainee trust a supervisor, which would reduce 
the sense of vulnerability one might experience in supervision. Likewise, if a supervisee views a supervisor as more self-disclosing, it is possible that the therapist-in-training would speak freely about how spirituality relates to therapeutic and supervisory processes. Given that spirituality is often personal, self-disclosing supervisors might create a more comfortable environment in which therapists, too, could disclose about spirituality. These findings coincide with Ratliff et al.'s (2000) study, which indicated that there is "a pattern of interaction that shows respect on the part of both supervisors and trainees for one another's autonomy" (p. 381).

Such findings also connect with several authors' assertions that spirituality is relational (Bava et al., 2002; Carlson \& Erickson, 2002; Carlson et al., 2002). Carlson et al. (2002) discussed that maintaining a "stance of critical reflexivity" would facilitate an open atmosphere between people, whether clients and therapists, or supervisees and supervisors. The theoretical foundation of these practices stems from narrative therapy; however, authors working from other theories also advocate this approach in supervision. Prouty (2001), for example, discovered in her research that feminist supervisors emphasized being open, committed, supportive, and available to supervisees. In general, a feminist approach would advocate a collaborative relationship (Wheeler et al., 1989). Different aspects of supervisory style also relate to whether power differentials are emphasized or minimized. Foucault's core concept of power as relational also makes sense in the context of supervision. His metaphor of a pastor/leader/shepherd applies to these findings (Foucault, 1978, p. 123). Perhaps a supervisee needs to gain acceptance from the supervisor with her/him in order to feel free and safe enough to discuss 
spirituality. If a supervisor behaves in an affiliative manner and is self-disclosing, she/he would facilitate the process of attaining a new subjective truth through a supervisory conversation about spirituality (Foucault, 1978).

\section{Gender and Supervisory Style}

No significant relationships were found between sex of therapist and ratings of supervisory style. As previously mentioned in relation to supervisory style and the frequency with which spirituality is addressed in supervision, it seems as if female therapists and male therapists perceive their supervisors in a similar manner. The findings coincide with Long et al.'s (1996) original assessment of the SSI, which also looked at AAMFT approved supervisors. They concluded that there is "a relative lack of differences in perceptions of supervisors' styles by the ... supervisee's sex and gender" (pp. 600-601).

With sex of supervisor and ratings of supervisory style, there were significant group differences between sex of supervisor only in the Affiliative/Authoritative subscale. Although no interaction effect was found between therapist sex and supervisor sex, which coincides with the one-way ANOVA run with sex of supervisor, a significant main effect was established for sex of supervisor with the Affiliative/Authoritative level. It is interesting that male supervisors were rated as more affiliative than female supervisors, which challenges the stereotype (where supervisors are concerned) that women are more relationally oriented than men. Moorhouse and Carr (2002) discovered similar results in their study of supervisory discourse in live supervision. They found that 
"the way supervisors interact with therapists ... does not conform to gender stereotypic conversational behaviour" (p. 55). One possible explanation of this result is that female and male supervisors in the field of family therapy do not conform to gender stereotypes and so men in this field may be perceived as even more open and affiliative than their female counterparts (McHale \& Carr, 1998; Moorhouse \& Carr, 2002). Another possible explanation is that MFT training helps clinicians expand their behavior beyond the stereotypes in supervision, which could lead to female supervisors developing a more directive style and male supervisors a more affiliative, collaborative style ( $\mathrm{McHale} \&$ Carr, 1998; Moorhouse \& Carr, 2002).

\section{Spirituality and Gender}

As reported in the previous chapter, no relationship was found between the sex of the therapist and frequency of spiritual issues addressed in supervision, as well as between the sex of the supervisor and frequency of spiritual issues addressed in supervision. It seems, therefore, that there is no difference between reports of male trainees and female trainees in their perspectives on spirituality discussed in supervision. Likewise, it did not seem to matter whether supervisees were rating female supervisors or male supervisors—apparently spirituality was being addressed with similar frequencies.

This lack of gender difference relates to Moorhouse and Carr's (2002) findings indicating that the way in which supervisors interact with trainees does not influence supervisory discourse in a gender stereotypic manner. 
It is possible that training programs are doing a better job treating therapists similarly, regardless of the sex of the trainee. Perhaps the attention paid to gender in supervision in recent years has helped raise the awareness of supervisors in MFT training programs.

In contrast, Anderson et al.'s (2000) study of MFT trainees' evaluations of best and worst supervision experiences did in fact indicate a gender difference in supervisors. Results suggested that even through the "gender of the supervisor in the best experiences was distributed somewhat evenly, nearly two-thirds of the supervisors in the worst experiences were reported to be male" (Anderson et al., 2000, pp. 84-85). It is important to emphasize that the gender differences delineated in Anderson et al.'s (2000) research were not found in the present study. At least when it comes to addressing spirituality in supervision, male supervisors and female supervisors were perceived similarly.

Although there was no significant relationship when examining sex of the therapist with addressing spirituality and sex of the supervisor with addressing spirituality, a significant effect was found when looking at the therapist sex by supervisor sex interaction. These results suggest that male therapists scored male supervisors as addressing spirituality more frequently than female supervisors. The interaction also indicates that female therapists rated female supervisors as addressing spirituality more frequently than male supervisors. These findings relate to McHale and Carr's (1998) study of the effect of supervisor's sex and trainee therapist's sex on supervision discourse. They discovered that "a collaborative supervision style was consistently associated with trainee therapist participation (either cooperatively or with resistance) 
within same gender pairings of supervisors and trainee therapists" (p. 408). McHale and Carr's (1998) results indicate, therefore, that same-sex supervisor/therapist pairs tended to be more collaborative in nature than different-sex pairs. Not only does the finding of the present study suggest that supervisory style is an important facet of therapist participation, it also shows that gender contributes to the supervision experience. It would seem, then, that there is something about same-sex supervisory pairs that makes it easier for spirituality to be addressed than with opposite-sex pairs.

Given the highly emotional and controversial nature of spirituality (Stander et al., 1994), perhaps it would be easier to delve into this area with a person of the same sex. Possibly the inherent power differential in the supervisory relationship is less pronounced in same-sex supervisory pairs than in other-sex supervisory pairs, which would help individuals discuss such a difficult topic. Knudson-Martin (2001) asserted that in therapy gender issues can be intertwined with spirituality, emphasizing that attending to both issues can be confusing, "especially in cases where gender equality and religious beliefs appear to be in conflict" (p. 4). It would seem, then, that gender and spirituality would also overlap in supervision. For example, a female therapist may feel more at-ease addressing gender equity and spirituality with a female supervisor because she might feel less intimidated than she would with a man, even if he was perceived as affiliative. In this case, the therapist's background could contribute to her level of comfort, especially if she has participated in religious organizations in which only males hold leadership positions.

McHale and Carr's (1998) research emphasized the importance of training programs recognizing that there may be factors hindering an open discourse in different- 
sex therapist/supervisor pairs. In the present study, findings suggested that there may be something about the relational interactions of other-sex, trainee-supervisor pairs that keep people from discussing spirituality in a free and open manner. Spirituality in supervision is a new area in MFT. Perhaps future research can demonstrate that these hindrances can be overcome. There needs to be more dialogue about spirituality and how gender and spirituality intersect, not only between supervisors and therapists, but in the MFT field in general. Without such dialogue, we will not be able to discover if these barriers can be overcome.

The interaction effect that emerged in this study also relates to the previously mentioned concept that spirituality is relational. Again, Foucault's theory of power is relevant. Strenski (1998) explored Foucault's discussion of religion and power, emphasizing how politically loaded the term religion is. Like gender, it seems as if religion "is now, and for the foreseeable future will be, one of the ways people divide and categorize human experience, institutions, and history" (Strenski, 1998, p. 357). It is interesting to point out that Freud strongly influenced both gender issues and spirituality in the realm of psychotherapy (Foucault, 1978; Strenski, 1998). It seems, therefore, that a lot of Foucault's work on issues of sexuality and religion stemmed from a response to Freud's prominent theories-and both are areas of political struggle (Foucault, 1978; MacLeod \& Durrheim, 2002; Strenski, 1998). Feminist family therapists have long pointed out the political nature of power issues in therapy (Haddock et al., 2000), and it seems that these issues are extremely relevant to supervision. As Flaskas and Humphreys (1993) stated, 'the question is being raised as to whether the effect of not naming 'power' 
and more particularly its abuse is more toxic in its consequences for clients than the potential harmfulness of naming power" (p. 38). Perhaps, then, supervisors need to recognize the power that they have in the relationship and understand how it can influence their interactions with trainees.

It is notable that female therapist/female supervisor pairs were rated with a higher frequency of discussing spirituality in supervision than female therapist/male supervisor pairs. Even though male therapist/male supervisor pairs scored higher than male therapist/female supervisor pairs, they were still rated lower than female/female pairs. This difference, however, may not be statistically significant. Perhaps there is something about the topic of spirituality that leads to interaction effects. As Foucault stated, it is in the relationship that power issues emerge (Foucault, 1978). Power also leads to the construction of a "normalizing judgment" as power interactions create hierarchies (Keenan, 2001). Historically, power and religion have intertwined, as illustrated in Foucault's illustration of a pastor/leader guiding the flock (Foucault, 1978). Possibly a supervisor, too, leads or guides a therapist-in-training, which may come into play as they discuss spirituality in this context. For Foucault, power emerges through such a relationship. Furthermore, several other authors contended that it is the relationship that is inherently spiritual (Bava et al., 2002; Carlson \& Erickson, 2002; Carlson et al., 2002). Overall, it appears that one must attend to the relational, rather than the individual, in order to consider how these issues interact, which fits completely with the systemic framework of MFTs. 


\section{Clinical Implications/Recommendations}

Based on the findings of this study, several recommendations can be made to therapists, supervisors, supervisees, and training programs in MFT. In essence, this study is the first type of research in the MFT field that actually studies spirituality in the supervisory context, albeit from the supervisee's perspective.

First, it is helpful to recognize that exploring spirituality as a facet of supervision is a viable practice. Although spirituality is a multifaceted construct that is often difficult to measure, it emerges through relationships and interactions between people, which is a central part of supervision. Not only does addressing spirituality correlate with aspects of supervisory style, which are recognized influences on the supervisory process (Long et al., 1996), it also relates to gender, which is also acknowledged as an important issue to consider when looking at power differentials in relationships (Zimmerman \& Haddock, 2001). It is important to point out that trainees perceive that spirituality is being addressed in different areas of supervision to some degree. The viability of the SISS, due to the promising evidence of reliability and validity that emerged both with participants in the pilot study and in the primary analyses, suggests spirituality is a construct that can be addressed in the supervisory context. As spirituality is examined in research, presented in the literature, and discussed at conferences, MFTs will become more comfortable in addressing this area in practice.

For trainees and supervisors, one of the implications of this study is that it is essential to examine the gender pairings of supervisors/supervisees, given how the gender composition of the supervisory relationship can influence the openness and affiliation one 
experiences in supervision. Other-sex pairings also could shape the degree to which spirituality is perceived to be addressed or intuited in supervision. Trainees could think about how they experience spirituality in relationship with their supervisors. For supervisors, it is imperative to acknowledge how their gender may influence how supervisees perceive supervision. Perhaps it would be helpful to follow the recommendations of several feminist family therapists and researchers and make gender an overt topic of conversation-especially with supervisees of the other sex (Prouty, 2001; Prouty et al., 2001; Zimmerman \& Haddock, 2001). Supervisors should launch discussions with trainees about what would get in the way of them talking about spirituality as it relates to supervision. Furthermore, supervisors can link gender and spirituality and converse about how the two areas intertwine in therapy, in supervision, and in one's life.

In the area of training programs, Prest et al.'s (1999) research found that MFT graduate students in the United States generally view both themselves and their clients as spiritual beings. Most of the participants suggested that training should focus on this area, as they do not believe that they are equipped adequately to address spirituality in MFT practice. It is likely that supervisors and faculty members working in these programs are not yet sanctioned and/or prepared to explore this area; therefore, understanding that it is a viable part of MFT research and clinical work would help them feel more comfortable with the topic.

MFT graduate programs can make two adjustments in their training to help both students and faculty gain the skills, experience, and knowledge to feel more equipped to 
talk about spirituality. First, programs could expose students to spiritual issues and how they relate to therapy by implementing a seminar, as described in Patterson et al.'s (2000) article, or by using part of a diversity class to address spirituality. A seminar and/or part of a class could include bringing in guest speakers representing different religious traditions and spiritual beliefs. Practical application through role-play scenarios could also help students learn how to converse with clients about this area, as well as assist therapists in knowing when to refer them to clergy members (Patterson et al., 2000). A second suggestion is intentionally integrating spirituality as part of the supervisory discourse. For example, a supervisor could have the supervisee complete a spiritual genogram (Frame, 2001) to explore her/his self-of-therapist issues in regards to this topic. Moreover, a supervisor could apply questions outlined in several articles (Carlson \& Erickson, 2000, 2001; Frame, 2001; Haug, 1998) to generate conversation about spirituality and its role in therapy. Above all, making an effort to integrate spiritual issues systemically throughout the training process (as has been done with gender and sex in the past) will equip therapists to explore this area on many professional and personal levels in their lives.

\section{Limitations}

There were several limitations that may have influenced the results of this study. The first limitation is clearly the difficulties inherent in measuring such an abstract concept as spirituality. Although Miller and Thoresen (2003) and Wendel (2003) asserted that spirituality indeed can be studied scientifically, it must be noted that the problems 
inherent in defining such a multifaceted construct make measuring it a challenge as well. In addition, even though the researcher included a specific definition of spirituality on the SISS as a reference for respondents, it does not guarantee that they interpreted spirituality similarly, given their varied experiences and viewpoints.

Another possible limitation is that there were unequal groups in the ANOVA analyses; however, given that these calculations were "simple one-way between-subjects ANOVA, problems created by unequal group sizes are relatively minor" (Tabachnick \& Fidell, 1996). At the same time, there were more female participants than male participants, which meant that in testing the hypotheses that included sex of therapist as a variable, group sizes became more discrepant. Such discrepancies would affect the assumption of homogeneity of variance, which maintains that the group variances are equal (Dickter \& Roznowski, 1996). Above all, this research reflected the nature of the population of therapists in MFT training programs.

The variations in group size lessened considerably when analyzing supervisor sex, as most participants rated one female supervisor and one male supervisor, providing nearly equal groups. The differences in female supervisor groups versus male supervisor groups ranged from three to eight, which are negligible. Two analyses in which adjustments were made to create more equal groups occurred in testing the interaction effects between therapist sex and supervisor sex. As previously stated in Chapter IV, most of the therapists were coded twice, and a few participants were coded once if they rated only one supervisor. This adjustment is not cited as a standard strategy for addressing the issue of unequal $n$, such as randomly deleting cases from cells or 
performing an unweighted-means analysis (Tabachnick \& Fidell, 1996); however, it made sense given the methodology for this study. It is also important to consider the selection effect; for example, a therapist could have chosen the supervisor that addressed spirituality more frequently than his/her other supervisors.

Most participants rated two supervisors, so in order to examine the therapist/supervisor pairs, the therapist would have to be counted twice because it was she/he who had supervision with both supervisors. A lack of independence of data (or nonorthogonality), therefore, could have affected the results because one therapist rated two supervisors, so correlation may have existed between the two ratings of each individual subject (Tabachnick \& Fidell, 1996). In future research, it would be helpful to conduct a repeated measures or within-subjects ANOVA, which takes into consideration the interaction of individual differences with each score (Tabachnick \& Fidell, 1996).

A third limitation is the variations in supervision format from program to program, which would influence the responses on the SSI. At some MFT graduate schools, trainees do not experience live supervision, which affected several questions on this instrument. Indeed, many participants either wrote "not applicable" or simply did not respond to SSI statements such as "The supervisor phones in directives at least three times per hour during live supervision." On the SSI subscales that had more of those type of statements (Affiliative/Authoritative and Non-Directive/Directive), there were fewer respondents.

With the SISS, another limitation was present. Given that several participants had attended supervision for only one academic year in their respective MFT programs, it was 
possible that several topic areas listed on the SISS (e.g., abortion, death) had not been addressed in supervision. Although some participants wrote "not applicable" on individual items, it is possible that other respondents simply gave a best guess on the degree to which spirituality would be addressed in a particular topic area. It would be helpful in the future to specify on the measure how participants should respond if they have not discussed a certain topic in supervision in order to insure more complete responses.

An additional limitation of this study is that it was based solely on the perspectives of the trainees. Although exploring the supervisors' perceptions of the supervisory experience extended outside the scope of this study, it would have been more systemic and more thorough to attain the supervisors' responses as well. In essence, one notable conclusion of this research is that spirituality, gender, and supervisory style can be measured best in a relational context such as supervision. At the same time, the researcher examined the perspectives of only one side of the relationship — namely, the trainees. It is also important to remember that supervisees have had fewer experiences in therapy and supervision than their supervisors, so it is likely that the lenses with which they interpret their supervisory experiences would be tainted with feelings of inadequacy and discomfort in the new role as clinician. Lee et al. 's (2001) study of first-year MFT students writing in a journal daily about critical incidents indicated that trainees felt very overwhelmed and uncertain when working with their cases. These feelings, in addition to the self-of-therapist issues students work out in supervision, suggest that other factors not considered in this study may have contributed to how they reported on the supervisory 
process. Similar limitations were mentioned in McHale and Carr's (1998) research article:

[T] here was the possibility that characteristics of supervisors, therapists and clients, which were neither randomized nor counterbalanced across the four conditions of the study, could have had an unknown, yet significant, effect on the results. This effect could have occurred because supervisor, therapist and client characteristics may have separately influenced supervisory discourse or because the way in which supervisors, therapists and clients were combined may have led to some supervisory systems having different interactional characteristics from others. (pp. 408-409)

In essence, the fact that the trainees were not randomly assigned to the supervisor (a process that was out of the control of this research) may have created therapist-supervisor pairs that had interactional characteristics not accounted for in this study. The participants represented a diverse stratum of the MFT student population in the U.S. from 12 different training programs; however, it is possible that programs assigned supervisees to supervisors intentionally, not randomly - and the reasons behind these assignments cannot be known or included as a control variable. It is also important to point out that many respondents likely described supervisory experiences they went through with other trainees, which would also shape the interactions and discourses that occur in supervision.

One last limitation is addressing the confounding variables in this study. As mentioned in Chapter IV, a few variables generated on the demographic questionnaire correlated with total scores for the SSI subscales, as well as the total SISS score. Even though these variables fell outside the focus of this research, it is possible that they influenced the results to some degree. It would be important, therefore to consider other 
variables that could influence clinicians' perceptions and experiences in future research. Although variables such as race, religious orientation, age, and considering oneself a spiritually minded person did not correlate with the SSI subscale scores and the SISS sum score in this study, it would be remissive not to explore these areas in the future.

\section{Future Directions}

Several possibilities emerge for future directions in research with this subject. These future directions could take several paths; however, this section will focus on the areas of therapy, supervision, and training. In the realm of clinical work, the SISS could be adjusted to apply to what occurs in the therapy room. Instead of a Spiritual Issues in Supervision Scale, it could become a Spiritual Issues in Therapy Scale (SITS). Although the new measure would be based upon the perspectives of the therapist, it would explore another relationship in which spirituality emerges as a relevant issue. Another possibility is to convert the hypothetical SITS to something with which someone could code clinician-client interactions. One would have to make the coding form very specific, which would take away from the perceptions of someone actually participating in the relational experience-something that has been discussed in this study as an integral aspect of spirituality. A final suggestion in regards to clinical work is to create focus groups of MFTs to explore phenomenologically their experiences with attending to spirituality in therapy.

With supervision, a logical next step would be to have supervisors complete the SISS in order to explore how they perceive the frequency with which spirituality is 
addressed in supervision. Researchers could then compare the perceptions of supervisors and supervisees in the same study. One possibility is to target one specific training program and randomly assign therapists and supervisors to lessen the possibility of other factors influencing supervisor/supervisee pairings. From a qualitative standpoint, researchers could either interview supervisors or conduct focus groups with them, exploring their experiences with spirituality in supervision. Qualitative methods might elicit more depth and delve into the complexities of supervisory relationships. Another option would be to videotape supervision sessions at several training programs and conduct a discourse analysis on the transcripts in order to examine how spirituality is actually being integrated into the process of supervision.

For MFT graduate training, Prest et al. (1999) had an idea of surveying the faculty in COAMFTE accredited programs concerning their attitudes and practices in training and therapy in regards to spirituality. With such a study, the authors suggested that researchers look at how "family and marital therapy theories and models of practice accommodate including this content? Where do they need to be refined or broadened?" (Prest et al., 1999, p. 75). It appears, therefore, that one would need to examine what is keeping faculty from addressing spirituality, which could occur through surveys, interviews, or focus groups. It would also be interesting to compare MFT programs in religious-oriented universities and seminaries with graduate schools in non-religious institutions in order to determine if differences exist between the two types. Researchers could implement the SISS in such a venture. Above all, it would be beneficial to examine 
the influence training programs have on whether or not spirituality is addressed in supervision and the classroom. 


\section{REFERENCES}

American Association for Marriage and Family Therapy Commission on Accreditation for Marriage and Family Therapy Education and Training. (Version 10.0). Manual on accreditation. Washington, DC: Author.

Anderson, S. A., Schlossberg, M., \& Rigazio-DiGilio, S. (2000). Family therapist trainees' evaluations of their best and worst supervision experiences. Journal of Marital and Family Therapy, 26, 79-92.

Aponte, H. (2002, January/February). God and therapy. Family Therapy Magazine, 1, 1621.

Ault-Riché, M. (1988). Teaching an integrated model of family therapy: Women as students, women as supervisors. Journal of Psychotherapy and the Family, 3, 175192.

Avis, J. M., \& Turner, J. (1996). Feminist lenses in family therapy research. In D. H. Sprenkle, and S. M. Moon (Eds.) Research methods in family therapy (pp. 145169). New York: Guilford.

Baber, K. M., \& Allen, K. R. (1992). Women and families: Feminist reconstructions. New York: Guilford.

Bava, S., Burchard, C., Ichihashi, K., Irani, A., \& Zunker, C. (2002). Conversing and constructing spirituality in a postmodern training context. Journal of Family Psychotherapy, 13, 237-258.

Blanton, P. G. (2002). The use of Christian mediation with religious couples: A collaborative language systems perspective. Journal of Family Psychotherapy, 13. 291-307.

Borysenko, J. (1999). A woman's journey to God. New York: Riverhead.

Boyd-Franklin, \& Lockwood, T. W. (1999). Spirituality and religion: Implications for psychotherapy with African American clients and families. In F. Walsh (Ed.), Spiritual resources in family therapy (pp. 90-103). New York: Guilford.

Brawer, P. A., Handal, P. J., Fabricatore, A. N., Roberts, R., \& Wajda-Johnston, V. A. (2002). Training and education in religion/spirituality within APA-accredited clinical psychology programs. Professional Psychology: Research and Practice, 33, 203-206. 
Campbell, D. T., \& Stanley, J. C. (1963). Experimental and quasi-experimental designs for research. Chicago: Rand McNally.

Carlson, T. D., \& Erickson, M. J. (2000). Re-authoring spiritual narratives: God in persons' relational identity stories. Journal of Systemic Therapies, 19, 65-83.

Carlson, T. D., \& Erickson, M. J. (2001). Honoring and privileging personal experience and knowledge: Ideas for a narrative therapy approach to the training and supervision of new therapists. Contemporary Family Therapy, 23, 199-220.

Carlson, T. D., \& Erickson, M. J. (2002). A conversation about spirituality in marriage and family therapy: Exploring the possibilities. Journal of Family Psychotherapy, 13. $1-11$.

Carlson, T. D., Erickson, M. J., \& Seewald-Marquardt, A. (2002). The spiritualities of therapists' lives: Using therapists' spiritual beliefs as a resource for relational ethics. Journal of Family Psychotherapy, 13, 215-236.

Carrette, J. R. (Ed.) (1999). Religion and culture: Michel Foucault. New York: Routledge.

Chaney, S. E., \& Piercy, F. P. (1988). A feminist family therapy behavior checklist. The American Journal of Family Therapy, 16, 305-318.

Coffey, A. D. (2002). Spirituality: Lives and relationships in family-therapy concepts and practices. Journal of Family Psychotherapy, 13, 29-52.

Dankoski, M. E., Penn, C. D., Carlson, T. D., \& Hecker, L. L. (1998). What's in a name? A study of family therapists' use and acceptance of the feminist perspective. The American Journal of Family Therapy, 26, 95-104.

Dickter, D. N., \& Roznowski, M. (1996). Basic statistical analyses. In F. T. L. Leong \& J. T. Austin (Eds.), The psychological research handbook (pp. 208-218). Thousand Oaks, CA: Sage.

Derflinger, K. R. (1997). Graduate students' perceptions of formative faculty characteristics: A look at what facilitates integrative development in a Christian psychology program (Doctoral dissertation, Rosemead School of Psychology, Biola University, 1997). Dissertation Abstracts International, 57 3414. (8-A)

Drabble, M. (1985). The oxford companion to English literature $\left(5^{\text {th }}\right.$ ed.). Oxford: Oxford University Press. 
Ellison, R. (1996). The king of the bingo game. In J. F. Callahan (ed.), Flying home and other stories (pp. 339-345). New York: Random House.

Erickson, M. J., Hecker, L., Kirkpatrick, D., Killmer, M., \& James, E. (2002). Clients' perceptions of marriage and family therapists addressing religious and spiritual aspects of clients' lives: A pilot study. Journal of Family Psychotherapy, 13, 109125 .

Falicov, C. J. (1999). Religion and spiritual folk traditions in immigrant families:

Therapeutic resources with Latinos. In F. Walsh (Ed.), Spiritual resources in family therapy (pp. 104-120). New York: Guilford.

Filkowski, M. B., Storm, C. L., York, C. D., \& Brandon, A. D. (2001). Approaches to the study of gender in marriage and family therapy curricula. Journal of Marital and Family Therapy, $27,117-122$.

Flaskas, C., \& Humphreys, C. (1993). Theorizing about power: Intersecting the ideas of Foucault with the "problem" of power in family therapy. Family Process, 32, 3547.

Forster, E. M. (1978). A passage to India. London: E. Arnold. (Original work published 1924)

Foucault, M. (1978). Sexuality and power (translated by Richard A. Lynch). In J. R. Carrette (Ed.) (1999), Religion and culture: Michel Foucault, pp. 115-130. New York: Routledge.

Frame, M. W. (2000a). Spiritual and religious issues in counseling: Ethical considerations. The Family Journal: Counseling and Therapy for Couples and Families, 8, 72-74.

Frame, M. W. (2000b). The spiritual genogram in family therapy. Journal of Marital and Family Therapy, 26, 211-216.

Frame, M. W. (2001). The spiritual genogram in training and supervision. The Family Journal: Counseling and Therapy for Couples and Families, 9, 109-115.

Friedlander, M. L., \& Ward. L. G. (1984). Development and validation of the Supervisory Styles Inventory. Journal of Counseling Psychology, 31, 541-557.

Fukuyama, M. A., \& Sevig, T. D. (1997). Spiritual issues in counseling: A new course. Counselor Education and Supervision, 36, 233-244. 
George, D., \& Mallery, P. (2001). SPSS for Windows: 10.0 Update. Needham Heights, MA: Allyn \& Bacon.

Goldner, V. (1985). Feminism and family therapy. Family Process, 24 31-47.

Gorsuch, R. L., \& Miller, W. R. (1999). Assessing spirituality. In W. R. Miller (Ed.), Integrating spirituality into treatment: Resources for practitioners (pp. 47-64). Washington, DC: American Psychological Association.

Griffith, M. E., \& Griffith, J. L. (2002). Addressing spirituality in its clinical complexities: Its potential for healing, its potential for harm. Journal of Family Psychotherapy, 13, 167-194.

Griffith, B. A., \& Rotter, J. C. (1999). Families and spirituality: Therapists as facilitators. The Family Journal: Counseling and Therapy for Couples and Families, 7 , 161164.

Grossman, C. L. (2002, March 7). Charting the unchurched in America. USA Today, p. D01.

Gubi, P. M. (2001). An exploration of the use of Christian prayer in mainstream counselling. British Journal of Guidance and Counselling, 29, 425-434.

Haddock, S. A., MacPhee, D., \& Zimmerman, T. S. (2001). AAMFT master series tapes: An analysis of the inclusion of feminist principles into family therapy practice. Journal of Marital and Family Therapy, 27, 487-500.

Haddock, S. A., Zimmerman, T. S., \& MacPhee, D. (2000). The power equity guide: Attending to gender in family therapy. Journal of Marital and Family Therapy, 26, 153-170.

Hare-Mustin, R. T. (1978). A feminist approach to family therapy. Family Process, 17. 181-194.

Harris, S. M. (1998). Finding a forest among trees: Spirituality hiding in family therapy theories. Journal of Family Studies, 4, 77-86.

Haug, I. E. (1998). Spirituality as a dimension of family therapists' clinical training. Contemporary Family Therapy, 20, 471-483.

Heller, P. E., \& Wood, B. (2000). The influence of religious and ethnic differences on marital intimacy: Intermarriage versus intramarriage. Journal of Marital and Family Therapy, 26, 241-252. 
Helmeke, K. B., \& Bischof, G. H. (2002). Recognizing and raising spiritual and religious issues in therapy: Guidelines for the timid. Journal of Family Psychotherapy, 13. $195-214$.

Hodge, D. R. (2000). Spiritual ecomaps: A new diagrammatic tool for assessing marital and family spirituality. Journal of Marital and Family Therapy, 26, 217-228.

James, W. (1997). The varieties of religious experience. New York: Simon \& Schuster. (Original work published 1902)

Joanides, C. J. (1996). Collaborative family therapy with religious family systems. Journal of Family Psychotherapy, $7,19-35$.

Keating, T. (1994). Intimacy with God. New York: Crossroad.

Keenan, E. K. (2001). Using Foucault's "disciplinary power" and "resistance" in crosscultural psychotherapy. Clinical Social Work Journal, 23, 211-227.

Kelly, E. W. (1994). The role of religion and spirituality in counselor education: A national survey. Counselor Education and Supervision, 33,227-237.

Keoughan, P. F., \& Joanning, H. (2001, August/September). Crisis of faith within religious families. Family Therapy News, 32, 6-7.

Knudson-Martin, C. (2001, August/September). Spirituality and gender in clinical practice. Family Therapy News, 32, 4-5.

Kurtz, E. (1999). The historical context. In W. R. Miller (Ed.), Integrating spirituality into treatment: Resources for practitioners (pp. 19-46). Washington, DC: American Psychological Association.

Lee, R. E., Eppler, C., Kendal, N., \& Latty, C. (2001). Critical incidents in the professional lives of first year MFT students. Contemporary Family Therapy, 23, $51-61$.

Lewis, C. S. (1961). A grief observed. London: Faber and Faber.

Long, J. K., Lawless, J. J., \& Dotson, D. R. (1996). Supervisory styles index: Examining supervisees' perceptions of supervisory style. Contemporary Family Therapy, 18 , 589-606.

MacLeod, C., \& Durrheim, K. (2002). Foucauldian feminism: The implications of governmentality. Journal for the Theory of Social Behaviour, 32, 41-60. 
McDaniel, S. H., Lorenz, A., Waxman, D., \& Kotze, E. (1995). Taking it like a man: Stories of men in family therapy training. American Journal of Family Therapy, 23, 291-305.

McGoldrick, M., Anderson, C. M., \& Walsh, F. (1989). Women in families: A framework for family therapy. New York: W. W. Norton \& Co.

McHale, E., \& Carr, A. (1998). The effect of supervisor and trainee therapist gender on supervision discourse. Journal of Family Therapy, 20, 395-411.

McLaren, M. A. (1997). Foucault and the subject of feminism. Social Theory and Practice, 23, 109-128.

McCready, W. C. (1996). Applying sampling procedures. In F. T. L. Leong, and J. T. Austin (Eds.), The psychology research handbook (pp. 98-110). Thousand Oaks, CA: Sage.

Miller, M. M., \& Wieling, E. (2002). Points of connection and disconnection: A look at feminism and postmodernism in family therapy. Journal of Feminist Family Therapy, 14 (2), 1-19.

Miller, W. R. (1999). Diversity training in spiritual and religious issues. In W. R. Miller (Ed.), Integrating spirituality into treatment: Resources for practitioners (pp. 253263). Washington, DC: American Psychological Association.

Miller, W. R., \& Thoresen, C. E. (1999). Spirituality and health. In W. R. Miller (Ed.), Integrating spirituality into treatment: Resources for practitioners (pp. 3-18). Washington, DC: American Psychological Association.

Miller, W. R., \& Thoresen (2003). Spirituality, religion, and health: An emerging research field. American Psychologist, 58, 24-35.

Moorhouse, A., \& Carr, A. (2002). Gender and conversational behaviour in family therapy and live supervision. Journal of Family Therapy, 24, 46-56.

Nelson, T. S. (1996). Survey research in marriage and family therapy. In D. H. Sprenkle, and S. M. Moon (Eds.), Research methods in family therapy (pp. 447-468). New York: Guilford.

Osmond, M. W., \& Thorne, B. (1993). Feminist theories: The social construction of gender in families and society. In P. G. Boss, W. J. Doherty, R. LaRossa, W. R. Schumm, \& S. K. Steinmetz (Eds.), Sourcebook of family theories and methods: A contextual approach (pp. 591-625). New York: Plenum. 
Patten, M. L. (2000). Understanding research methods ( $2^{\text {nd }}$ ed.). Los Angeles: Pyrczak.

Patterson, J., Hayworth, M, Turner, C., \& Raskin, M. (2000). Spiritual issues in family therapy: A graduate-level course. Journal of Marital and Family Therapy, 26, 199210.

Prest, L. A., \& Keller, J. F. (1993). Spirituality and family therapy: Spiritual beliefs, myths, and metaphors. Journal of Marital and Family Therapy, 19, 137-148.

Prest, L. A., Russel, R., \& D'Souza, H. (1999). Spirituality and religion in training, practice and personal development. Journal of Family Therapy, 21, 60-77.

Prouty, A. (2001). Experiencing feminist family therapy supervision. Journal of Feminist Family Therapy, $12,171-203$.

Prouty, A. M., Thomas, V., Johnson, S., \& Long, J. K. (2001). Methods of feminist family therapy supervision. Journal of Marital and Family Therapy, 27, 85-98.

Ratliff, D. A., Wampler, K. S., \& Morris, G. H. B. (2000). Lack of consensus in supervision. Journal of Marital and Family Therapy, 26 373-384.

Reeves, D., Culbreth, J. R., \& Greene, J. R. (1997). Effect of sex, age, and education level on the supervisory styles of substance abuse counselor supervisors. Journal of Alcohol and Drug Education, 43, 76-86.

Schulte, D. L., Skinner, T. A., \& Claiborn, C. D. (2002). Religious and spiritual issues in counseling psychology training. The Counseling Psychologist, 30, 118-134.

Senter, K. E., \& Caldwell, K. (2002). Spirituality and the maintenance of change: A phenomenological study of women who leave abusive relationships. Contemporary Family Therapy, 24, 543-564.

Snyder, D. K., \& Mangrum, L. F. (1996). Approaches to prediction: Correlation, regression, and discriminant analysis. In D. H. Sprenkle and S. M. Moon (Eds.), Research methods in family therapy (pp. 307-335). New York: Guilford.

Sorenson, R. L. (1995). Integration of what? Implications of Gerald G. May's concept of willingness. Journal of psychology and Christianity, 14, 330.

Stander, V. Piercy, F. P., Mackinnon, D., \& Helmeke, K. (1994). Spirituality, religion and family therapy: Competing or complementary worlds? The American Journal of Family Therapy, 22, 27-41. 
Strenski, I. (1998). Religion, power, and final Foucault. Journal of the American Academy of Religion, 66, 345-367.

Tabachnick, B. G., \& Fidell, L. S. (1996). Using multivariate statistics $\left(3^{\text {rd }}\right.$ ed.). New York: HarperCollins.

Tan, A. (2001). The bonesetter's daughter. New York: Ballantine.

Tinsley, H. E. A., \& Tinsley, D. J. (1987). Uses of factor analysis in counseling psychology research. Journal of Counseling Psychology, 34, 414-424.

Trepper, T. S. (2002). Preface. Journal of Family Psychotherapy, 13, xvii-xviii.

VanMeter, J. B., McMinn, M. R., Bissell, L. D., Kaur, M., \& Pressley, J. D. (2001). Solitude, silence, and the training of psychotherapists: A preliminary study. Journal of Psychology and Theology, 29, 22-28.

Vatcher, C.-A., \& Bogo, M. (2001). The feminist/emotionally focused therapy practice model: An integrated approach for couple therapy. Journal of Marital and Family Therapy, 27, 67-84.

Walters, M., Carter, B., Papp, P., \& Silverstein, O. (Eds.) (1988). The invisible web: Gender patterns in family relationships. New York: Guilford.

Walsh, F. (Ed.) (1999). Spiritual resources in family therapy. New York: Guilford.

Wendel, R. (2003). Lived religion and family therapy: What does spirituality have to do with it? Family Process, 42, 165-179.

Watson, M. F. (1993). Supervising the person of the therapist: Issues, challenges and dilemmas. Contemporary Family Therapy, 15, 21-31.

Wheeler, D., Avis, J., Miller, L., \& Chaney, S. (1989). Rethinking family therapy training and supervision: A feminist model. In M. McGoldrick, C. Anderson \& F. Walsh (Eds.), Women in families: A framework for family therapy (pp. 135-151). New York: W. W. Norton.

White, M., \& Epston, D. (1990). Narrative means to therapeutic ends. New York: Norton.

Zimmerman, T. S., \& Haddock, S. A. (2001). The weave of gender and culture in the tapestry of a family therapy training program: Promoting social justice in the practice of family therapy. Journal of Feminist Family Therapy, 12, 1-31. 
APPENDLX A

DEMOGRAPHIC QUESTIONNAIRE 


\section{For multiple choice questions, please circle your responses.}

General Information:

1) What is your age?

2) What is your sex?
a) Female
b) Male

3) What is your ethnicity?
a) Native American or Alaska Native
b) Asian or Pacific Islander
c) African-American (Black)
d) Latino/a
e) European-American (Anglo)
f) Other (please specify):

4) What is your current relationship status?
a) Single
b) Cohabiting, no children
c) Cohabiting, children
d) Married, no children
e) Married, with children
f) Separated
g) Divorced
h) Other:

5) Describe your student status:
a) First-year masters
b) Second-year masters
c) Third-year and higher masters
d) First-year doctoral
e) Second-year doctoral
f) Third-year doctoral
g) Fourth-year doctoral
h) Fifth-year and higher doctoral
i) Other: 


\section{Your Epistemological Orientation as a Therapist:}

6) In general, how would you describe your epistemological orientation?
a) Modern
b) Postmodern
c) Other:

7) Would you consider yourself a feminist family therapist?

(For the purposes of this survey, a feminist family therapist is defined as a person who intentionally attends to issues of gender, power, hierarchy, oppression, and marginalization)
a) Yes
b) No

\section{Epistemological Orientation of Supervisors:}

For question 8, you will need to choose one male full-time, part-time, or adjunct faculty supervisor you have had in your current program. For question 9, you will need to choose one female full-time, part-time, or adjunct faculty supervisor. If you have had either no female faculty supervisors or no male faculty supervisors, please choose d) Not applicable.

8) In general, how would you describe your male supervisor's epistemological orientation?
a) Modern
b) Postmodern
c) Other:
d) Not applicable

9) In general, how would you describe your female supervisor's epistemological orientation?
a) Modern
b) Postmodern
c) Other:
d) Not applicable

Please remember the supervisors you have chosen to answer questions 8 and 9. You will apply your answers to these same supervisors when you fill out two copies of the Spiritual Issues in Supervision Scale (SISS), as well as two copies of the Supervisory Styles Index (SSI). 
Number and Sex of Supervisors:

10) How many full-time, part-time, or adjunct faculty supervisors have you had in the MFT program in which you are currently enrolled? (Please count the supervisor you currently have, if she/he is a faculty member)
a) 1
b) 2
c) 3
d) 4
e) $5+$

11) Out of those full-time, part-time, or adjunct faculty supervisors that you have had, how many of them are female?
a) 0
b) 1
c) 2
d) 3
e) 4
f) $5+$

12) How many of the full-time, part-time, or adjunct supervisors you have had are male?
a) 0
b) 1
c) 2
d) 3
e) 4
f) $5+$

Spirituality:

13) In general, do you consider yourself a spiritually minded person?
a) Yes
b) No

14) Using the following continuum, indicate the percentage of time you attend to spirituality and/or spiritual issues in therapy:

$0 \%$ of the time $-100 \%$ of the time 
15) Using the following continuum, indicate the percentage of time the full-time, parttime, or adjunct faculty members in your current program attend to spirituality and/or spiritual issues in the classroom:

$0 \%$ of the time-1.-.-.-100\% of the

16) Using the following continuum, indicate the percentage of time the full-time, parttime, or adjunct faculty members attend to spirituality and/or spiritual issues in supervision:

$0 \%$ of the time-- $100 \%$ of the time

17) With which type of religious organization, if any, are you affiliated?
a) None
b) Jewish
c) Protestant Christian (e.g.
d) Catholic
e) Latter-Day Saints (Mormon)
f) Buddhist
g) Hindu
h) Islamic/Muslim
i) Other:

18) Do you actively participate in a religious organization?
a) Yes
b) No

19) In the space provided below, please describe how you define spirituality for yourself: 
APPENDIX B

SUPERVISORY STYLES INDEX (SSI) 


\section{THE SUPERVISORY STYLES INDEX (SSI) FEMALE SUPERVISOR}

Response Categories: 4. Agree

3. Tend to agree

2. Tend to disagree

1. Disagree

Affiliative/Authoritative Subscale

1. The supervisor is respectful of my opinions about the therapy process.

2. The supervisor asks for my input about what is going on with the client(s).

3. In team supervision, the supervisor uses ideas from trainees for phone-ins from behind the mirror.

4. The supervisor recognizes me as a person with expertise.

5. The supervisor expects me to be in charge of my case load.

6. In a team meeting, the supervisor dominates the discussion.

Non-Directive/Directive Subscale

7. The supervisor expects me to develop the plan for an upcoming therapy session rather than providing one for me.

8. The supervisor phones in directives at least three times per hour during live supervision.

9. The supervisor develops the final intervention to be used in a session.

10. The supervisor develops the homework tasks given to the client(s) at the end of the session.

11. The supervisor enters the session when he/she feels that I am not being effective.

12. The supervisor insists on strict adherence to her/his directives.

Self Disclosing/Non-Self-Disclosing Subscale

13. The supervisor openly shares examples from her/his own experiences as a therapist.

14. The supervisor is willing to discuss how his/her family-of-origin issues affected his/her performance in therapy.

15. The supervisor acknowledges his/her own limitations

16. The supervisor discloses how current issues in her/his life affect the supervision process.

17. The supervisor admits when she/he makes a mistake.

18. The supervisor is open about his/her own life.

19. The supervisor spends very little time joining with supervisees. 


\title{
THE SUPERVISORY STYLES INDEX (SSI) MALE SUPERVISOR
}

\author{
Response Categories: 4. Agree \\ 4. Tend to agree \\ 3. Tend to disagree \\ 2. Disagree
}

Affiliative/Authoritative Subscale

1. The supervisor is respectful of my opinions about the therapy process.

2. The supervisor asks for my input about what is going on with the client(s).

3. In team supervision, the supervisor uses ideas from trainees for phone-ins from behind the mirror.

4. The supervisor recognizes me as a person with expertise.

5. The supervisor expects me to be in charge of my case load.

6. In a team meeting, the supervisor dominates the discussion.

Non-Directive/Directive Subscale

7. The supervisor expects me to develop the plan for an upcoming therapy session rather than providing one for me.

8. The supervisor phones in directives at least three times per hour during live supervision.

9. The supervisor develops the final intervention to be used in a session.

10. The supervisor develops the homework tasks given to the client(s) at the end of the session.

11. The supervisor enters the session when he/she feels that I am not being effective.

12. The supervisor insists on strict adherence to her/his directives.

Self Disclosing/Non-Self-Disclosing Subscale

13. The supervisor openly shares examples from her/his own experiences as a therapist.

14. The supervisor is willing to discuss how his/her family-of-origin issues affected his/her performance in therapy.

15. The supervisor acknowledges his/her own limitations

16. The supervisor discloses how current issues in her/his life affect the supervision process.

17. The supervisor admits when she/he makes a mistake.

18. The supervisor is open about his/her own life.

19. The supervisor spends very little time joining with supervisees. 
APPENDIX C

SPIRITUAL ISSUES IN SUPERVISION SCALE (SISS) 


\section{Spirituality in Supervision Scale (SISS) FEMALE SUPERVISOR}

In the Demographic Questionnaire, you chose one female full-time, part-time, or adjunct faculty member in your MFT program to respond to question 9. According to the following scale, please rate how often spirituality is addressed when certain issues arise in supervision with this female supervisor. If you have never had a female full-time, part-time, or adjunct faculty member who has been a supervisor in your current program, please choose another male supervisor and write $M A L E$ on the top of this form.

Below are several circumstances in which spirituality could be addressed in supervision. This measure examines your perceptions of the supervision experience with a particular sex of supervisor.

Spirituality is defined in the broadest sense as an overarching construct that includes a personal journey of transcendent beliefs and a sense of connection with other people, experienced either within or outside of formal religious structures.

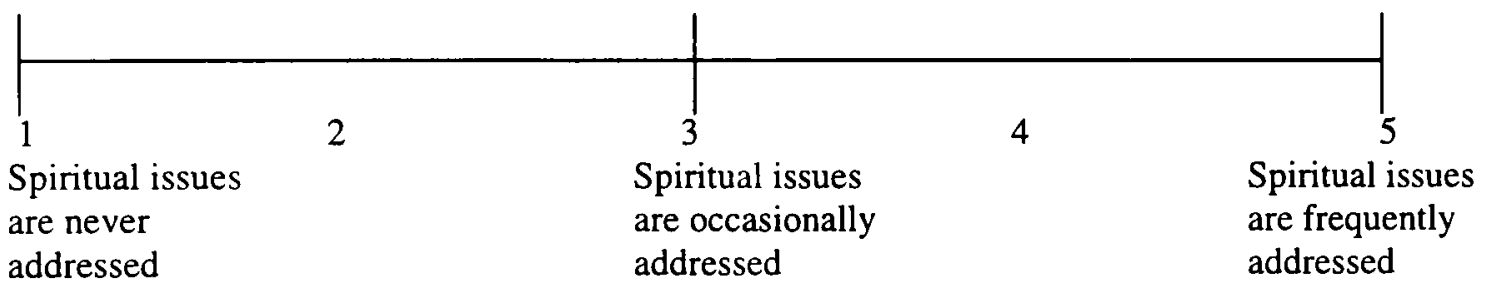
1) When the assessment process is discussed
2) In the area of grief, loss, and death
3) With issues concerning marriage
4) With issues concerning divorce
5) When discussing gender issues
6) With self-of-therapist issues, including your own family-of-origin issues
7) When talking about the treatment plan
8) When conceptualizing the case (e.g., integrating theory of therapy)
9) With substance abuse issues
10) In the area of trauma (including abuse)
11) When self-esteem issues emerge
12) With themes of morality and/or values
13) With issues about sexual orientation
14) In the area of culture
15) When addressing ethnicity 
Spirituality is defined in the broadest sense as an overarching construct that includes a personal journey of transcendent beliefs and a sense of connection with other people, experienced either within or outside of formal religious structures.

\begin{tabular}{ll|ll|} 
& & & \\
\hline 1 & 2 & & 5 \\
$\begin{array}{l}\text { Spiritual issues } \\
\text { are never }\end{array}$ & 3 & 4 & Spiritual issues \\
addressed & $\begin{array}{l}\text { Spiritual issues } \\
\text { are occasionally } \\
\text { addressed }\end{array}$ & & $\begin{array}{l}\text { are frequently } \\
\text { addressed }\end{array}$
\end{tabular}

16) When addressing race

17) When discussing parenting issues

18) When discussing other issues concerning children

19) _ In the area of identity

20) _ When talking about the supervisory relationship

21) With issues about sexual intimacy

22) __ With ethical concerns

23) When addressing issues of power and hierarchy

24) With issues surrounding abortion

25) __ With issues concerning contraception or fertility

26) __ In the area of suicide/suicidal ideations

27) __ With the theme of a personal network or support group for the clients

28) ___ About your own personal network or support group

29) ___ When talking about hope or a greater purpose in life

30) When discussing religion 


\section{Spirituality in Supervision Scale (SISS) MALE SUPERVISOR}

In the Demographic Questionnaire, you chose one male full-time, part-time, or adjunct faculty member in your MFT program to respond to question 9. According to the following scale, please rate how often spirituality is addressed when certain issues arise in supervision with this male supervisor. If you have never had a female full-time, part-time, or adjunct faculty member who has been a supervisor in your current program, please choose another female supervisor and write FEMALE on the top of this form.

Below are several circumstances in which spirituality could be addressed in supervision. This measure examines your perceptions of the supervision experience with a particular sex of supervisor.

Spirituality is defined in the broadest sense as an overarching construct that includes a personal journey of transcendent beliefs and a sense of connection with other people, experienced either within or outside of formal religious structures.

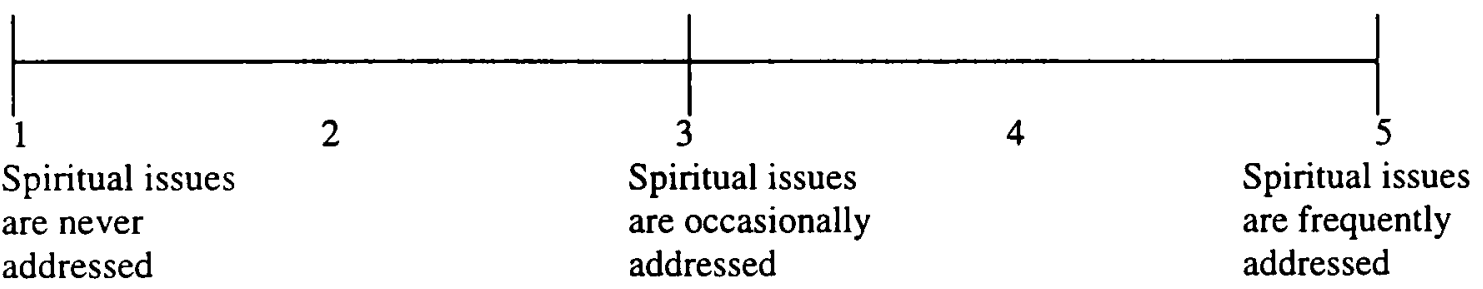

31) When the assessment process is discussed

32) In the area of grief, loss, and death

33) With issues concerning marriage

34) With issues concerning divorce

35) When discussing gender issues

36) With self-of-therapist issues, including your own family-of-origin issues

37) When talking about the treatment plan

38) When conceptualizing the case (e.g., integrating theory of therapy)

39) With substance abuse issues

40) In the area of trauma (including abuse)

41) When self-esteem issues emerge

42) With themes of morality and/or values

43) With issues about sexual orientation

44) In the area of culture

45) When addressing ethnicity 
Spirituality is defined in the broadest sense as an overarching construct that includes a personal journey of transcendent beliefs and a sense of connection with other people, experienced either within or outside of formal religious structures.

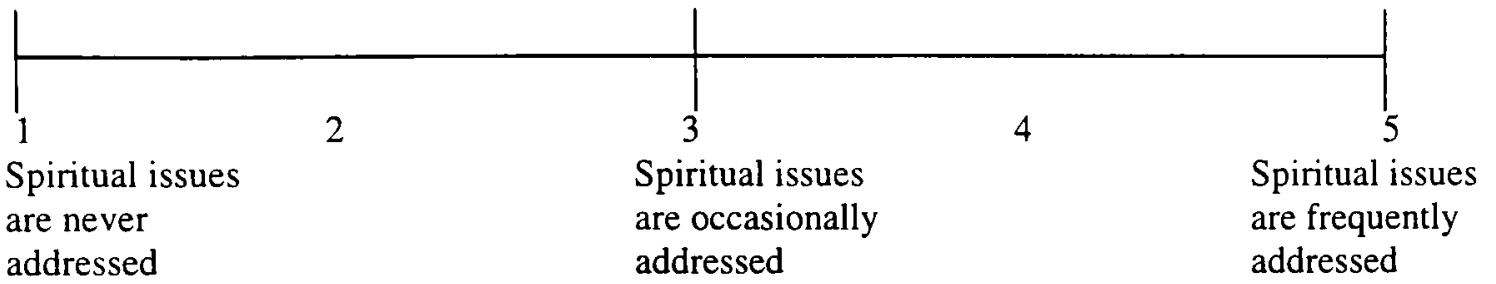

\begin{tabular}{|c|c|}
\hline 46) & When addressing race \\
\hline 47) & When discussing parenting issues \\
\hline 48) & When discussing other issues concerning children \\
\hline 49) & In the area of identity \\
\hline 50$)$ & When talking about the supervisory relationship \\
\hline 51) & With issues about sexual intimacy \\
\hline 52) & With ethical concerns \\
\hline 53) & When addressing issues of power and hierarchy \\
\hline 54) & With issues surrounding abortion \\
\hline 55) & With issues concerning contraception or fertility \\
\hline 56$)$ & In the area of suicide/suicidal ideations \\
\hline 57) & With the theme of a personal network or support group for the clients \\
\hline 58) & About your own personal network or support group \\
\hline 59) & When talking about hope or a greater purpose in life \\
\hline 60) & When discussing religion \\
\hline
\end{tabular}

